Article

\title{
Economic Analysis of an Integrated Production-Inventory System under Stochastic Production Capacity and Energy Consumption
}

\author{
Iqra Asghar *,+(D), Biswajit Sarkar *,+(-) and Sung-jun Kim \\ Department of Industrial and Management Engineering, Hanyang University, Ansan Gyeonggi-do 15588, Korea \\ * Correspondence: iqra_ntu60@yahoo.com (I.A.); bsbiswajitsarkar@gmail.com (B.S.); Fax: +82-31-400-5959 (B.S.) \\ + These authors contributed equally to this work.
}

Received: 1 June 2019; Accepted: 14 August 2019; Published: 19 August 2019

check for updates

\begin{abstract}
Expensive power cost is a significant concern in today's manufacturing world. Reduction in energy consumption is an ultimate measure towards achieving manufacturing efficiency and emissions control. In the existing literature of scheduling problems, the consumption of energy is considered uncertain under the dimensions of uncertain demand and supply. In reality, it is a random parameter that also depends on production capacity, manufacturing technology, and operational condition of the manufacturing system. As the unit production cost varies with production rate and reliability of the manufacturing system, the energy consumption of the system also varies accordingly. Therefore, this study investigated an unreliable manufacturing system under stochastic production capacities and energy consumption. A stochastic production-inventory policy is developed to optimize production quantity, production rate, and manufacturing reliability under variable energy consumption costs. As energy consumption varies in different operational states of manufacturing, we consider three specific states of power consumption, namely working, idle, and repair time, for an integrated production-maintenance model. The considered production system is subjected to stochastic failure and repair time, where productivity and manufacturing reliability is improved through additional technology investment. The robustness of the model is shown through numerical example, comparative study, and sensitivity analysis of model parameters. Several graphical illustrations are also provided to obtain meaningful managerial insights.
\end{abstract}

Keywords: stochastic production capacity; unreliable production system; energy; random failure and repair rates; controllable production rate

\section{Introduction}

Today's fastest growing economies are forcing manufacturers to decrease the processing time of products along with providing lower costs and better quality. To maintain a better position in such a competitive market, manufacturers are needed to be highly automated, integrated, and flexible in their production capacities. Therefore, manufacturing technology is developing day by day with improved qualities such as high flexibility, smart operations, and adaptability. However, since initial capital investment and operating costs are high for smart automation, advanced manufacturing industries are concerned with managing their manufacturing system utilization to the absolute maximum limit. Regardless of acquiring elevated levels of automation, flexibility, and high-quality products, without a reliable costing mechanism, manufacturing systems cannot stay competitive with changing economic environment. Therefore, manufacturing productivity requires a stable and reliable manufacturing system for decreasing the setup time and production lead-time. Recently, Sarkar et al. [1] proposed an analytic procedure to investigate manufacturing setup and lead time 
reduction strategies through additional investments in manufacturing system, where setup cost improvement for a two-stage production system is addressed in [2]. Rapid economic recovery is the ultimate desire of manufacturing organizations due to intense market competition and globalization. Moreover, maintaining the productivity of the manufacturing process is the basic criterion of a manufacturing business. In this regard, Kumar et al. [3] developed structured optimal policies for the financial aspects of a product under the imperfect production process. The study shows that a manufacturing firms should devise optimal strategies for the product development process to survive in the market. Further, costs associated with an automation policy in smart manufacturing system were discussed by Sarkar et al. [4]. In this context, the significance of energy costs for the production process and manufacturing costs is worth examination as it serves as a substantial part of production costs in manufacturing industries. For instance, in the electronics industry, the energy costs represent up to $2 \%$ of total production costs. Manufacturing industry consumes up to $35 \%$ of energy production globally [5]. Similarly, in textile and printing industries, the share of energy cost is up to $2 \%$ of total production costs. The impact of energy costs is more influential in the heavy metal industry, as it takes 35\% share in production costs, whereas in oil refineries, it reaches up to $65 \%$. In the existing literature, energy cost management has been studied for factors related to generation and consumption of energy. On the other hand, this study involved improving production-inventory management with respect to energy control variables related to production and maintenance policies. These energy control variables are related to manufacturing reliability and manufacturing capacity and are improved through technology investments. Generally, energy consumption is considered as a variable or semi-variable cost item as energy consumption can reach up to $50 \%$ or more for some manufacturing organizations. Therefore, energy cost is considered as a controllable factor with critical influential effects on the expenses of manufacturing.

From an economic perspective, the lower energy consumption leads to lower manufacturing costs. From the environmental perspective, lower consumption leads to energy saving along with cost-effective factor. It reduces carbon emissions and the need to generate extra energy on behalf of Earth resources. Reducing the energy consumption of production system is also necessary because a large part of greenhouse gas emission, from production activities, comes from energy generation. In many production systems, this percentage reaches almost $100 \%$, as stated by Bazan et al. [6]. Energy optimization problems are studied for job-shop and flow-shop system by many authors (e.g., Giret et al. [7] and Liu et al. [8]). Energy-efficient production planning (EEPP) is the basic need of manufacturing systems. In this regard, Biel and Glock [9] provided energy pricing based production planning for sustainable manufacturing system. The study considers the renewable energy incorporation in production planning along with fixed pricing strategy. Higher energy prices and strict green legislation are big challenges for today's manufacturing industry. Liu et al. [10] developed a bi-objective optimization problem to reduce idle time energy consumption and devise energy saving strategies. A comprehensive review of energy efficient production planning was provided by Biel and Glock [9]. Economic lot sizing problem with the energy consumption aspects was investigated by Rapine et al. [11], whereas energy efficient manufacturing process chains was discussed by Mousavi et al. [12]. Recently, González-Romera et al. [13] investigated the renewable energy consumption for smart community under consumer comfort level considerations. Advance equipment reduces the energy consumption significantly when consider for scheduling problems, as stated by Mori et al. [14]. Shrouf et al. [15], Tang et al. [16] and Dai et al. [17], among others, investigated the flexible flow-shop system for energy consumption. Li et al. [18] developed a scheduling problem for a flexible manufacturing system. Recently, renewable energy problems were discussed by Calicioglu et al. [19]. Smart grid system and HV grid system for high quality energy production was discussed by Pramangioulis et al. [20]. The energy management of residential hubs for demand and storage system along with environmental concerns were investigated by Brahman et al. [21]. Routing problems for energy consumption based vehicles is another area of energy management which is significantly explored by researchers [22]. More recently, Sarkar et al. [23] investigated the electric 
power distribution system under online to offline $(\mathrm{O} 2 \mathrm{O})$ supply chain management. Bazan et al. [24] noted that no paper considered energy consumption in inventory and supply chain models before 2014 . However, recently, energy consumption received the attention of researchers in the field of supply chain and inventory management. Bazan et al. [6] investigated energy consumption for production and transportation activities related to supply chain management. Bazan et al. [25] investigated closed-loop supply chain under energy usage from the production process.

Recently, Bazan et al. [24] studied supply chain coordination under energy consumption in two-echelon supply chain model. Sarkar et al. [26] studied a smart production system under energy usage. However, none of the existing models consider energy usage with an unreliable production system with stochastic machine failure and repair time. In such systems, the considerations of energy are more important compared to others, because machine breakdown increases the cost of energy usage for production process. According to Devoldere et al. [27], a certain fraction of energy consumption is always fixed for the manufacturing system irrespective of its working status. During a long-run production, a common phenomenon is the break down of the machine and production system. The system and machine break down results in higher energy usage and production of defective items [26]. The study shows that energy consumption is a critical factor as it raises the cost of the system, even if the smart production system is considered. Therefore, the consideration of energy in an unreliable production system is extremely important. However, unfortunately, energy cost receives very little attention of the researchers in the field of unreliable inventory and supply chain management. Sarkar et al. [28] studied financial implications of a random time of machine failure for a manufacturing process and developed an optimal Economic quantity model (EMQ) model with safety stock quantity. This study was further extended to imperfect production process by Sarkar et al. [29]. The study assumes that, with increased manufacturing unreliability, the manufacturing system moves from perfect production to imperfection production state. The study is further discussed with technology investment to improve the design variable of manufacturing system and reduce machine break downs [30]. Recently, Bhuniya et al. [31] extended the case of manufacturing reliability [26] for imperfect production process for bivariate dependent demand rate. Yao et al. [32] also developed manufacturing models based on manufacturing reliability for smart manufacturing. The influence of manufacturing unreliability under the effect of economical aspects is multi-fold, as investigated by Sarkar et al. [33]. The study discusses the effect of joint unreliability and inflation on an EMQ model. To increase the manufacturing reliability, this work introduces a technology development cost while treating reliability variable as a decision parameter.

Practically, the production rate of machines, intended to produce a product, can be controlled in modern manufacturing systems. If a manufacturing system allows such adjustments, production managers can directly change production rate to desired range, by changing labor working hours on manufacturing processes, and adding or removing idle hours in-between production runs. Manufacturing systems with controllable production rates are categorized as rigid or flexible production systems in the literature [34]. For rigid case, production rates are changed only at the start of a product run and then they stay constant throughout production period. In the variable/controllable scenario, the production rate is also changed during production process. Inventory literature that covers this stream of manufacturing based research focuses on production costs with respect to production rates and production up-time. Costs function associated with production rate of manufacturing system can be derived empirically, by computing the input parameter's quantity to produce one unit of finished product, at different production rates. A comprehensive overview of manufacturing literature in this research direction is given in [35]. Variable manufacturing system with unreliable machines has been discussed in the pioneering works of Rishel [36], Olsder and Suri [37] and, more recently, Glock [38]. In these studies, the machine failures and repair are discussed with Homogeneous Markov Process. For the first time, Khouja and Mehrez [39] examined a variable product rate model. They considered the production rate dependent production quality of system. Supply chain management under the joint effect of time varying holding cost and variable production rate was 
examined by Sarkar et al. [40]. Impact of variable production rate in a two-stage production system was studied by Alfares and Ghaithan [41]. They suggested that variable production rates also gives flexibility in production planning to smooth the flows of raw material and work-in-process inventories which helps to avoid bottlenecks at working stations. Production rate is considered as a dynamic variable in [42]. A single vendor, multi-buyer supply chain model is studied in [43], where vendor production cost changes with variable production rate. For multiple-buyers, a continuous-review inventory model is developed to inspect inventory levels in this study. In addition, a crashing cost is employed to reduce buyer's lead times. One major flaw in this research stream is that it only focuses on unit production cost associated with variable production rates. The effect of variable production rate on other production and inventory related costs such as maintenance, storage, and carrying is neglected in the existing research. In addition, the impact of energy consumption in the dimension of unreliable and random capacity manufacturing operations is still underdeveloped. The development of technology, advances the performance of manufacturing machines, and reduces production up-time by proposing a controllable production rate in manufacturing units. However, higher production rates would need higher operating/maintenance costs and may increase the machine failure rate. With controllable production rate, an increase of processing load on the manufacturing system leads to higher costs of energy consumption per unit time. Consequently, it is inevitable to change spare parts and plan maintenance schedules frequently for manufacturing system, and then the cost of maintenance would also rise. This way, manufacturing reliability and production rates become the energy control variables. Ultimately, it is important to examine the effect of manufacturing unreliability on variable production capacities and associated energy consumption. Therefore, this study investigated the impact of optimum production lot size, production rate and manufacturing reliability on manufacturing energy consumption. In particular, we optimize the integrated production-inventory-maintenance policy when the manufacturing system faces random failures and random repair times. The manufacturing energy consumption is considered accordingly for three manufacturing states of production system: in operation, in idle state and for system repair work.

In this paper, energy consumption with respect to consumed electric power for each manufacturing task and energy control variables is considered. This paper investigates the variable energy consumption effect with controllable production rate and gives the optimal level for additional tooling and technology developmental costs. The relationship between variable energy consumption and energy control factors (production rate and failure rate) is justified on two criteria. The first is that, as the controllable production rate in units/unit time is changed, the associated specific energy consumption rate (SEC) for manufacturing process in $\mathrm{kWh} /$ units will change accordingly. The higher production rate reduces the specific energy consumed per item for manufacturing process. With the reduction of production time, produced quantity counterbalances for the rise of energy consumed per hour. Similarly, as the number of manufacturing failures increases, the energy consumption per units produced will increase and accordingly extra energy requirements for production restoration and start-ups will arise. Increased number of manufacturing system break downs lead to increased machine warming and restore/re-setup energy, and thus it increases the energy consumption per unit of production. This way, variable energy consumption for manufacturing process has three different components: energy consumption during setup and operational time, energy consumption during idle time due to break down and energy requirements for maintenance/re-setup activities of manufacturing system. In this paper, production, and maintenance policy related energy control factors are improved to optimize energy consumption in the manufacturing industry. Since machine failure rate is highly dependent on the design variable of manufacturing system, quality of maintenance, and production rates, this paper investigates the electrical energy consumption rates of an unreliable manufacturing system with respect to maintenance and production management factors, namely production rate $p$ and failure rate $\phi$. Table 1 provides the existing contribution efforts of different authors in the proposed research area. 
Table 1. Research contributions by different authors.

\begin{tabular}{|c|c|c|c|c|c|}
\hline Author(s) & $\begin{array}{l}\text { Manufacturing } \\
\text { Reliability }\end{array}$ & $\begin{array}{l}\text { Maintenance } \\
\text { Policy }\end{array}$ & $\begin{array}{l}\text { Production } \\
\text { Capacity }\end{array}$ & $\begin{array}{l}\text { Development } \\
\text { Cost }\end{array}$ & Energy \\
\hline Marchi et al. [44] & variable & NA & variable & NA & considered \\
\hline Marchi et al. [45] & variable & NA & variable & NA & considered \\
\hline Bhuniya et al. [31] & variable & NA & variable & $(\phi)$ & considered \\
\hline Sarkar et al. [26] & variable & NA & variable & $(\phi)$ & considered \\
\hline Adane and Nicolescu [46] & NA & considered & constant & NA & NA \\
\hline Demichela et al. [47] & NA & considered & NA & NA & considered \\
\hline Li et al. [18] & NA & NA & flexible & NA & NA \\
\hline Rackow et al. [48] & NA & NA & energy flexible & NA & considered \\
\hline Shibin et al. [5] & NA & NA & flexible & NA & considered \\
\hline Lee and Prabhu [49] & NA & considered & energy-aware & NA & considered \\
\hline This study & stochastic & considered & controllable & $(p, \phi)$ & considered \\
\hline
\end{tabular}

$(\phi)$ means reliability dependent development cost. $(p, \phi)$ means reliability and production capacity dependent development cost. NA means not-applicable.

The rest of this paper is structured as follows. Section 2 addresses mathematical model formulation. Section 3 develops mathematical modeling of the proposed unreliable manufacturing system. Section 4 illustrates the developed mathematical model with numerical experiment and sensitivity analysis of model parameters. Finally, Section 5 concludes the study and suggests some future extensions.

\section{Problem Statement, Notation, and Assumptions}

This sections defines the problem statement and assumptions for the proposed mathematical model and notation used to develop mathematical model, which are given below.

\subsection{Problem Statement}

In this paper, an integrated production-inventory-maintenance policy is optimized under energy control variables named as production rate and manufacturing reliability. Moreover, the specific production energy consumption for each product is considered as a component of per unit manufacturing cost. The paper considers an unreliable manufacturing system which can be regulated at different production rates within design limits $\left(p \in\left[p_{\min }, p_{\max }\right]\right)$, resulting in different unit production costs. The variable production rate decrease production lead-time and per unit production cost. On the contrary, other manufacturing operation costs related to maintenance and spare parts replacement raise with higher production rates. The manufacturing system is subjected to stochastic failure rate and, on each random breakdown, it is immediately subjected to corrective repair. A minor restoration is required along with each corrective repair, which is also stochastic in nature. Now, optimal integrated production planning is developed under the influence of energy control variables, where, with the increase in production rate, the production up-time is reduced which also reduces the energy consumption for manufacturing. On the other side, higher production rates leads to higher break downs of system and energy requirements for maintenance activities. To increase productivity of manufacturing system, a production-technology development cost is considered. Moreover, to increase the reliability of manufacturing system, a separate technology development cost is also added in the system costs. Based on different operation states of manufacturing process, energy costs for three states of manufacturing system are considered: working state (setup + production), idle time (break down + process disruptions), and for maintenance activities (repair + restoration). 


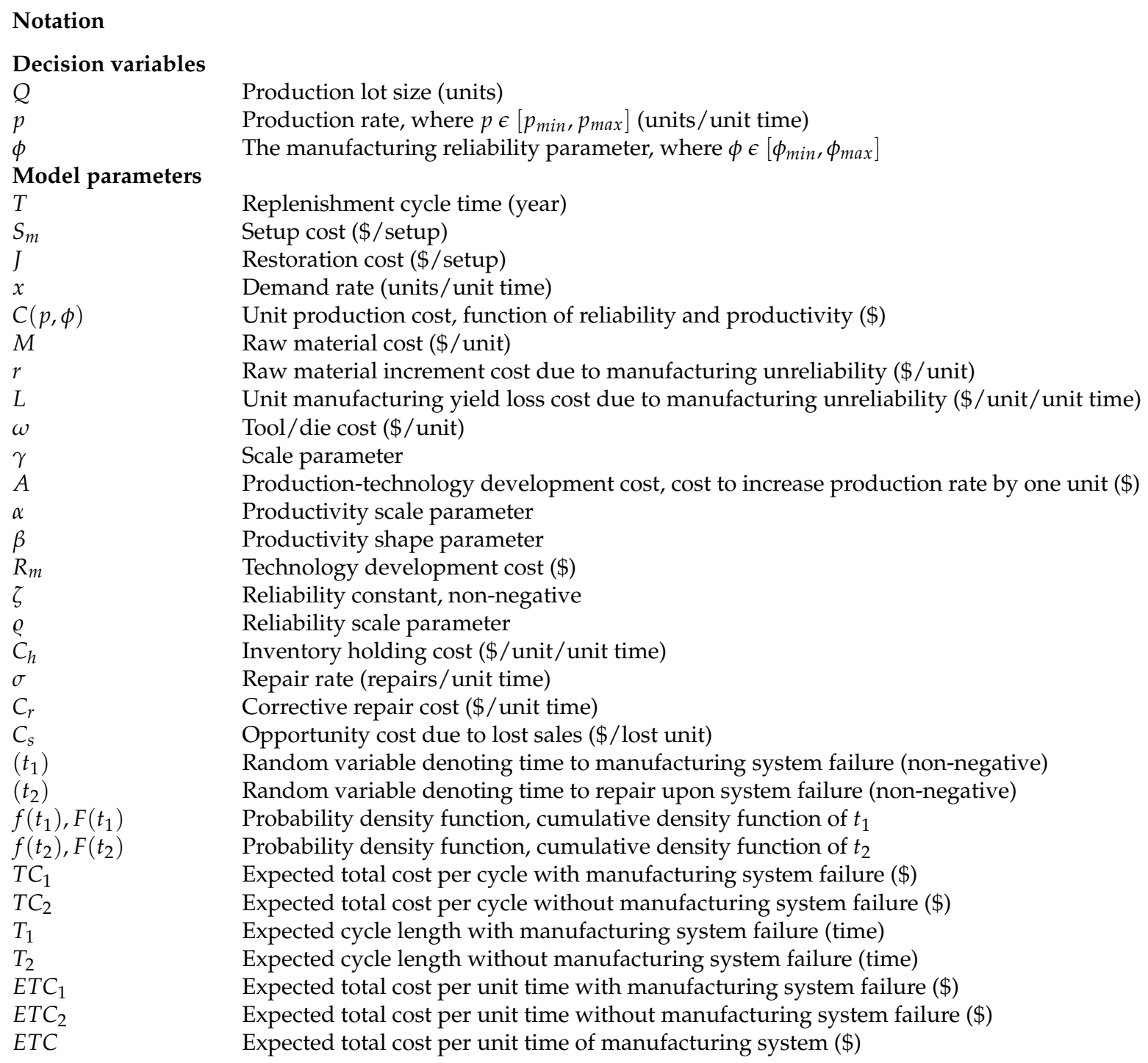

\subsection{Assumptions}

To model the proposed scenario mathematically, the following assumptions, apart from the previously stated ones, are considered.

- The demand rate of the products is known and constant, whereas the controllable production rate of manufacturing system is greater than demand rate $(p>x)$, and a decision variable.

- The unit production cost is not constant but a function of controllable processing rate and manufacturing unreliability.

- The reliability of the manufacturing system is derived through a stochastic process.

- The reliability of manufacturing system is expressed as a design variable, where it is represented as $\phi=\frac{\text { Total number of failure }}{\text { Total working hours }}$, and reliability can be increased through investment in production technology and manufacturing resources.

- The failure rate and repair rate are random variables and follow continuous probability distributions.

- The manufacturing reliability and production rate are considered as energy control variables, independent and additive.

- Shortages are considered for longer repair duration. 


\section{Mathematical Model}

This paper investigates an unreliable production-inventory model under controllable production rate and variable electrical energy consumption effects. In this context, an integrated production-maintenance policy is designed under the influence of random failure rate and random repair rate. The manufacturing system starts at time $(t=0)$ with a controllable production rate $\left(p \in\left[p_{\min }, p_{\max }\right]\right)$ to manufacture a production quantity $Q$. The production proceed until production up-time $\frac{Q}{p}$ and the inventory accumulates with the rate $(p-x) t_{m}$, if manufacturing system does not face any failure. The on-hand inventory is driven through differential equation as:

$$
\frac{\mathrm{dQ}_{1}(t)}{\mathrm{dt}}=(p-x), \quad\left(0 \leq t \leq t_{m}\right), \quad \text { with the initial condition } Q_{1}(0)=0,
$$

and

$$
\frac{\mathrm{dQ}_{2}(t)}{\mathrm{dt}}=(-x), \quad\left(t_{m} \leq t \leq T\right), \quad \text { with the given condition } I_{1}\left(t_{m}\right)=I_{2}\left(t_{m}\right) .
$$

The solution of above equations result,

$$
I(t)=\left[\begin{array}{cc}
(p-x) t & 0 \leq t \leq t_{m} \\
p t_{m}-x t & t_{m} \leq t \leq T
\end{array}\right]
$$

Since manufacturing system may face random breakdowns during production up-time, two cases arise for production planning. If time to breakdown is $\left(t<t_{m}\right)$, then a random breakdown take place during production up-time $t_{m}$ and corrective maintenance is started immediately. If failure occurs at $\left(t \geq t_{m}\right)$, then no failure is considered during production up-time. Therefore, two separate models are examined in the following section, as shown in Figure 1.

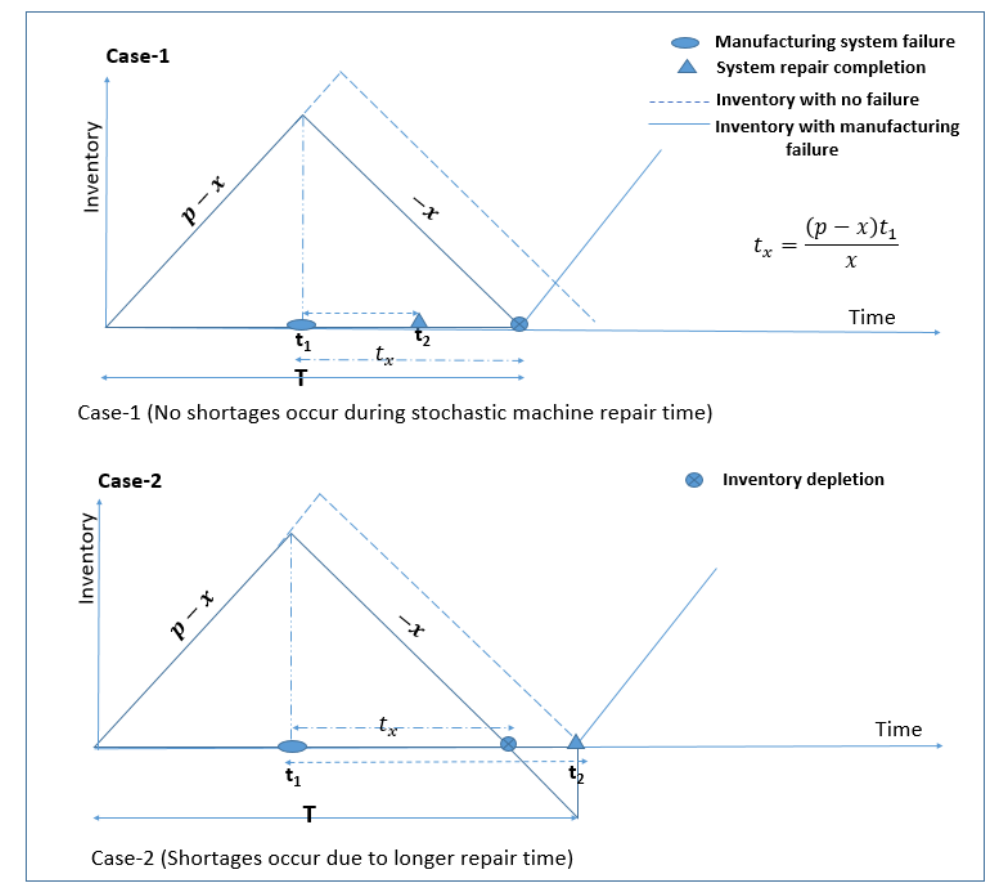

Figure 1. Inventory diagram for an unreliable manufacturing system. 


\subsection{Model 1: Random Production Capacity Model with Manufacturing System Failure}

In this case, at time $\left(t=t_{1}\right)$, the manufacturing system deteriorates and production system stops. The inventory accumulates during time interval $\left[0, t_{1}\right]$ and depletes with demand rate $x$ during $\left[t_{1}, T\right]$. Therefore, the expected total inventory becomes:

$$
\int_{0}^{t_{1}}(p-x) t d t+\int_{t_{1}}^{T}\left(p t_{1}-x t\right) d t
$$

As the repair rate is also a random variable, during stochastic repair time, two further cases may occur, as described in Figure 1.

\section{Case 1 (no shortages occur during stochastic repair time)}

This scenario is depicted in Case 1 of Figure 1, where the required time to repair manufacturing system after occurrence of failure is small enough that it lies within the on-hand inventory depletion time $\frac{(p-x) t_{1}}{x}$; then, expected inventory becomes,

$$
\operatorname{Inv}_{1}=\int_{0}^{\frac{Q}{p}}\left(\int_{0}^{\frac{(p-x) t_{1}}{x}}\left(\frac{p(p-x) t_{1}^{2}}{2 x}\right) f\left(t_{2}\right) d t_{2}\right) f\left(t_{1}\right) d t_{1}
$$

\section{Case 2 (shortages occur during stochastic repair time)}

Case 2 of Figure 1 represents the scenario of stochastic repair time where the required time to repair manufacturing system $\left(t=t_{2}\right)$ after failure is large enough that it exceeds the on-hand inventory depletion time $\frac{(p-x) t_{1}}{x}$; then, expected inventory becomes,

$$
\operatorname{Inv}_{2}=\int_{0}^{\frac{Q}{p}}\left(\int_{\frac{(p-x) t_{1}}{x}}^{\infty}\left(\frac{\left.p(p-x) t_{1}^{2}\right)}{2 x}\right) f\left(t_{2}\right) d t_{2}\right) f\left(t_{1}\right) d t_{1}
$$

and the expected shortages due to longer repair time are given as,

$$
\int_{0}^{\frac{Q}{p}}\left(\int_{\frac{(p-x) t_{1}}{x}}^{\infty}\left(x t_{2}-(p-x) t_{1}\right) f\left(t_{2}\right) d t_{2}\right) f\left(t_{1}\right) d t_{1} .
$$

Total production-maintenance cost per cycle $T C_{1}$ for combining the two cases consists of the variable setup cost, variable restoration cost, variable production-technology development cost, variable production costs, variable cost for repairing the manufacturing system, inventory holding costs, and shortage cost, which are given below.

\section{Energy costs}

The cost of energy consumption is considered as a variable/semi-variable cost parameter in the manufacturing industry. The management of energy variables is very important as the cost of energy consumption can reach up to $50 \%$ or more of the variable costs category of manufacturing costs. Therefore, to include energy costs for the unreliable manufacturing system, several new notations are introduced as follows. 


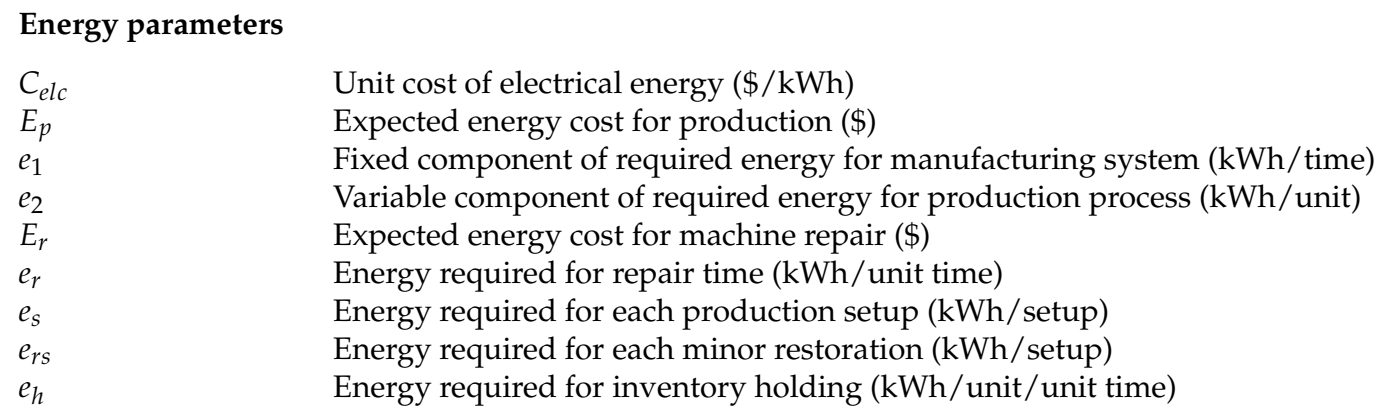

Marchi et al. [45] referred to production energy consumption as proportional to manufacturing rate, therefore, under variable production rate, a manufacturing system develops variable energy consumption states. As stated by Gutowski et al. [50], the average energy cost for production $E_{p}$ depends on the specific energy consumption per unit produced (SEC) which consist of two components: constant energy requirement $e_{1}\left(\mathrm{kWh} /\right.$ time) and variable energy requirement $e_{2}(\mathrm{kWh} / \mathrm{unit})$ for production process. Energy component $e_{1}$ is required for ready state functions of manufacturing system such as (e.g., lubrication, cooling, humidification, pressure pumps, and centrifugal energy) and variable energy component $e_{2}$ depends on the production rate of manufacturing system, therefore SEC for production becomes (see Bazan et al. [6]):

$$
\operatorname{SEC}(p)=\frac{e_{1}}{p}+e_{2}
$$

Energy costs for three states of manufacturing system for a production run are considered in the following section: working state (setup + production time), idle time (break down + process disruptions), and for maintenance activities (repair + restoration).

\section{Setup cost}

Setup cost for a manufacturing system varies with energy consumption for each production quantity and production rate. Frequent failures of manufacturing systems lead to raised warming of the system and consequent restart-up energy, which directly increases the energy consumption per unit of production. Considering that, generally, the failure rate of the manufacturing system is profoundly dependent on the quality of the operating system, this paper considers restoration cost as a function of reliability and initial setup cost of manufacturing system. In addition, as the manufacturing system faces random failure rate, on each failure $\phi$, a minor setup is carried out to restore the manufacturing system to initial operational conditions at a $\operatorname{cost}\left(\frac{J S_{m}}{\phi}\right)$. Thus, the model considers variable setup cost, variable restoration cost, expected energy consumption cost per setup, and expected energy cost for restoration for the manufacturing system as follow,

$$
S C(\phi)=S_{m}\left(1+\frac{J}{\phi}\right)+C_{e l c} e_{s}+\frac{C_{e l c} e_{r s}}{\phi} .
$$

\section{Production cost}

Productivity of an automated manufacturing system varies with the operating conditions, manufacturing system process quality and manufacturing costs. With variable productivity, the energy consumption of manufacturing system also varies. The variable manufacturing rate reduces the production up-time and production lead time, however some operational conditions such as cost of processing tools, maintenance and energy consumption increase conversely. As the manufacturing reliability defines the productivity per unit of time for manufacturing system, the productivity itself is an operational concept which shows the manufacturing throughput per unit of time. To improve the energy consumption and productivity of the manufacturing system, we consider a controllable 
production rate, which varies within designed limits $\left[p_{\min }, p_{\max }\right]$. As the production rate is a variable parameter, the unit production cost depends on energy control variables, production rate and failure rate of manufacturing system, as given below,

$$
C(p, \phi)=\frac{\left(c_{p}+L \phi\right)}{p}+p^{\gamma} \omega+(M+r \phi) .
$$

The unit production cost consists on several production rate and manufacturing reliability based components, which are explained below:

1. The cost component $(M+r \phi)$ is the cost of raw material, which increases linearly with increasing failure rate of manufacturing system.

2. The $c_{p}$ component represents the manufacturing costs, i.e., capital and labor costs, and, as the production rate increases, manufacturing cost is evenly distributed across a vast number of produced units. Consequently, the per unit manufacturing cost reduces with higher production rates (see Figure 2).

3. The next cost component is $L \phi$, which represents the manufacturing yield loss. As the failure rate of manufacturing system increases, the downtime increases and overall costs of system increases linearly (see Figure 3). However, with higher production rates, the unit yield loss cost decreases as the higher production rate reduces the production up-time and more items are produced in fewer working hours.

4. The last cost component is referred to as tool/die cost, and it is directly proportional to production rate.

5. The energy cost for production $E_{p}$ is given as a function of electrical energy consumption $C_{\text {elec }}$ $(\mathrm{kWh})$ based on controllable production rate. Therefore, expected energy cost for a production run is derived as a function of unit electricity cost $C_{\text {elc }}(\$ / \mathrm{kWh})$, specific energy required per item produced $S E C(p)(\mathrm{kWh} / \mathrm{unit})$, production up-time $t_{m}$ (hours), and production rate $p$ (units/unit time).

$$
E_{p}\left(C_{\text {elec }}\right)=C_{\text {elc }} S E C(p) p t_{m}
$$

Moreover, as the unit manufacturing cost is equally distributed over a wide range of produced products, per unit production cost becomes,

$$
C(p, \phi)=\frac{\left(c_{p}+e_{1}+L \phi\right)}{p}+e_{2}+p^{\gamma} \omega+(M+r \phi) .
$$

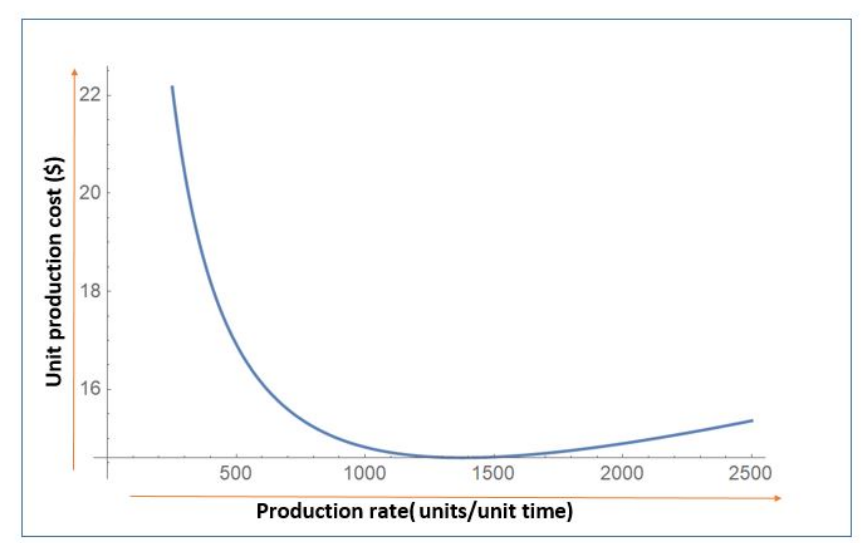

Figure 2. Change in per unit manufacturing $\operatorname{cost} C(p, \phi)$ with varying production rate $(p)$. 


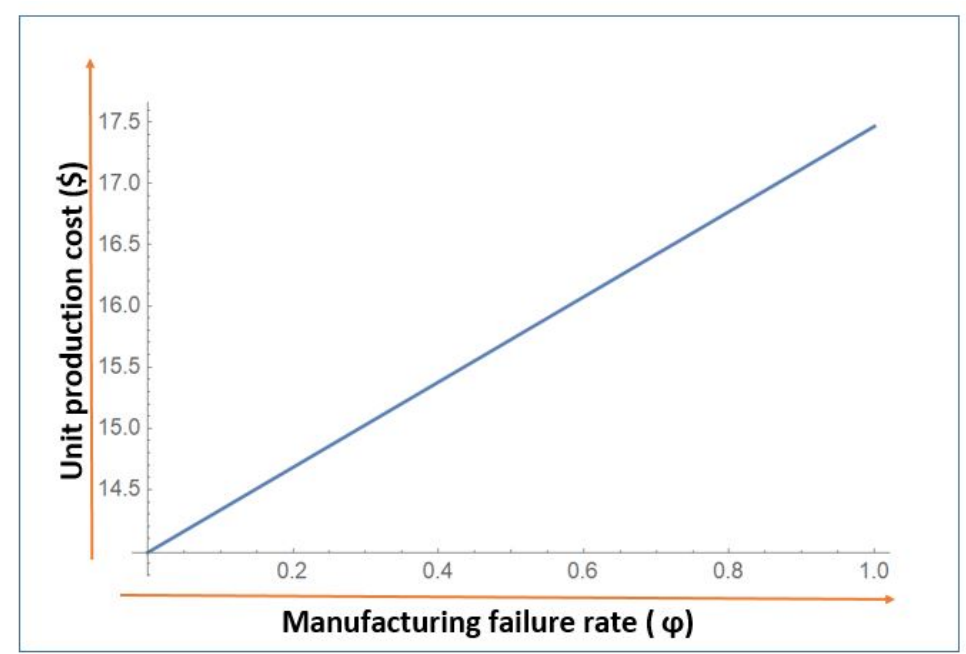

Figure 3. Change in per unit manufacturing $\operatorname{cost} C(p, \phi)$ with varying manufacturing reliability $(\phi)$.

As illustrated in Figure 4, specific energy consumption per unit $\operatorname{SEC}(p)$ decreases with an increase in production rate for the proposed model and eventually energy required to produce a single unit decreases [51].

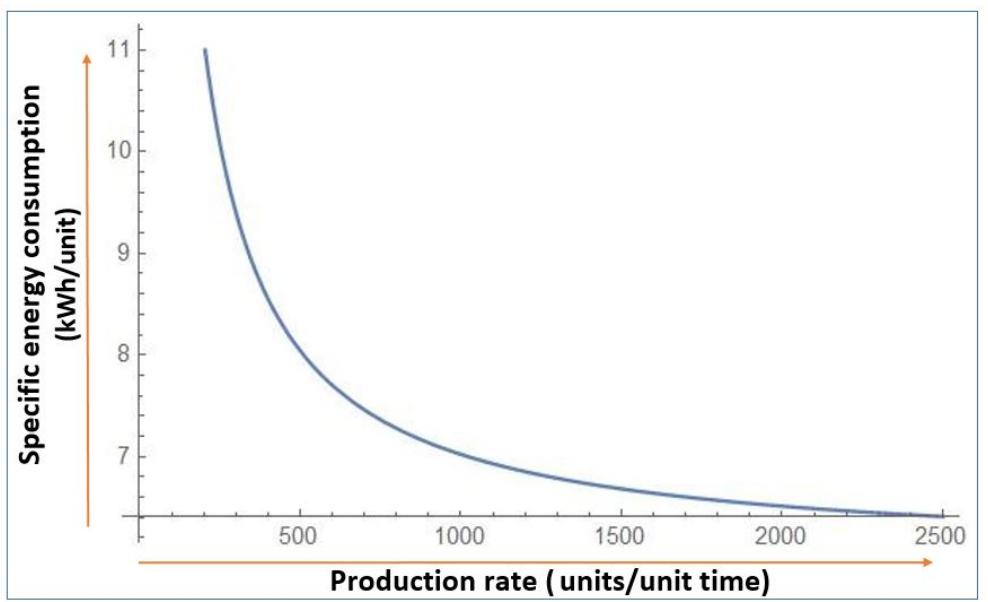

Figure 4. Change in specific energy cost (SEC) per unit manufactured with varying production rate $(p)$.

Hence, the expected total production cost becomes,

$$
\begin{aligned}
C P_{1}(p, \phi) & =\int_{0}^{\frac{Q}{p}}\left(\int_{0}^{\frac{(p-x) t_{1}}{x}}\left(p t_{1}\left(\frac{c_{p}+C_{e l c} e_{1}+\mathrm{L} \phi}{p}+C_{e l c} e_{2}+(M+\mathrm{r} \phi)+p^{\gamma} \omega\right)\right) f\left(t_{2}\right) d t_{2}\right) f\left(t_{1}\right) d t_{1} \\
& +\int_{0}^{\frac{Q}{p}}\left(\int_{\frac{(p-x) t_{1}}{x}}^{\infty}\left(p t_{1}\left(\frac{c_{p}+C_{e l c} e_{1}+\mathrm{L} \phi}{p}+C_{e l c} e_{2}+(M+\mathrm{r} \phi)+p^{\gamma} \omega\right)\right) f\left(t_{2}\right) d t_{2}\right) f\left(t_{1}\right) d t_{1} .
\end{aligned}
$$

As the production rate is measured as units/unit time, and the energy consumption is derived in $\mathrm{kWh} /$ units of production, which infer that, as the production rate increases, the specific energy consumption per unit manufactured decreases for given production up-time. In addition, higher production rates lead to higher utilization of machine working time and more goods are produced in less time. The same assertions are made in other recent studies $[6,44,45]$. 


\section{Production-technology development cost}

The productivity of a manufacturing system depends on a combination of system design parameters named as production capacity and production reliability. In modern automated manufacturing system, the manufacturing reliability and productivity can be improved through investment in advanced production technology, where manufacturing systems with more advanced technology are considered more reliable and efficient. For controllable production rates, the increase in the processing load of the production system increases the consumed electric power per unit time. As the manufacturing system can operate at higher production rates $\left(p \in\left[p_{\min }, p_{\max }\right]\right)$, the working life of manufacturing components shorten over time and the required frequency of tool change increases. Therefore, manufacturing systems with controllable production rates exhibit higher costs of processing tools for sustaining higher productivity. Eventually, it is essential to replace spare parts/tools of the manufacturing system quite often, which then increases the cost of manufacturing tools. To yield the development of manufacturing system to sustain higher productivity, we consider production-technology development $\operatorname{cost} G(p, \phi)$, as illustrated in Figure 5, as a function of controllable production rate and variable manufacturing reliability. Figure 5 shows that an increase in production unit by one unit results in the elevated machine stress requiring extra management costs as given below,

$$
G(p, \phi)=A \alpha\left(\frac{p-p_{\min }}{p_{\max }-p}\right) \beta+R_{m} e^{\frac{\zeta \phi}{\rho}}
$$

where $A$ is the cost of labor. Energy and extra management costs, which are dependent on manufacturing rate, $\alpha$ and $\beta$, are non-negative production constants. The productivity of the manufacturing system also depends on the operational condition of system, which is named as manufacturing reliability. To improve manufacturing reliability within the achievable limits, $\left(\phi \in\left[\phi_{\min }, \phi_{\max }\right]\right)$, a variable technology development cost is considered, as shown in Figure 6. $R_{m}$ is the cost of technology, resources, and energy for manufacturing system when it is absolutely reliable with failure rate $\left(\phi=\phi_{\min }\right)$. The constant $\zeta$ represents the difficulties in increasing reliability parameter due to limited technological resources and manufacturing system complexities, and $\varrho$ is a scale parameter, which shows the effectiveness of advanced manufacturing technology.

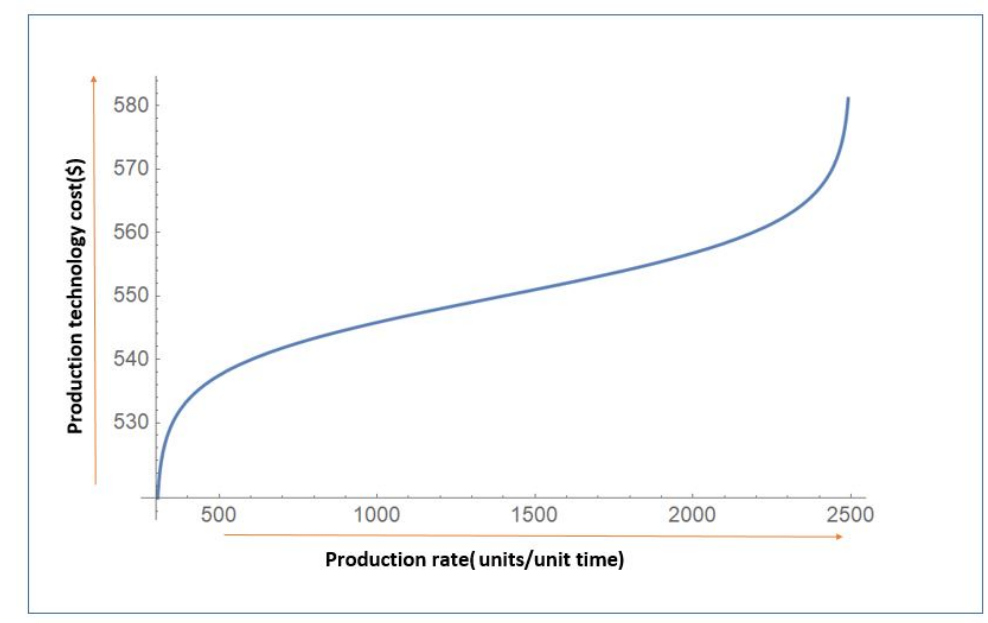

Figure 5. Change in production-technology development cost $G(p, \phi)$ with varying production rate $(p)$. 


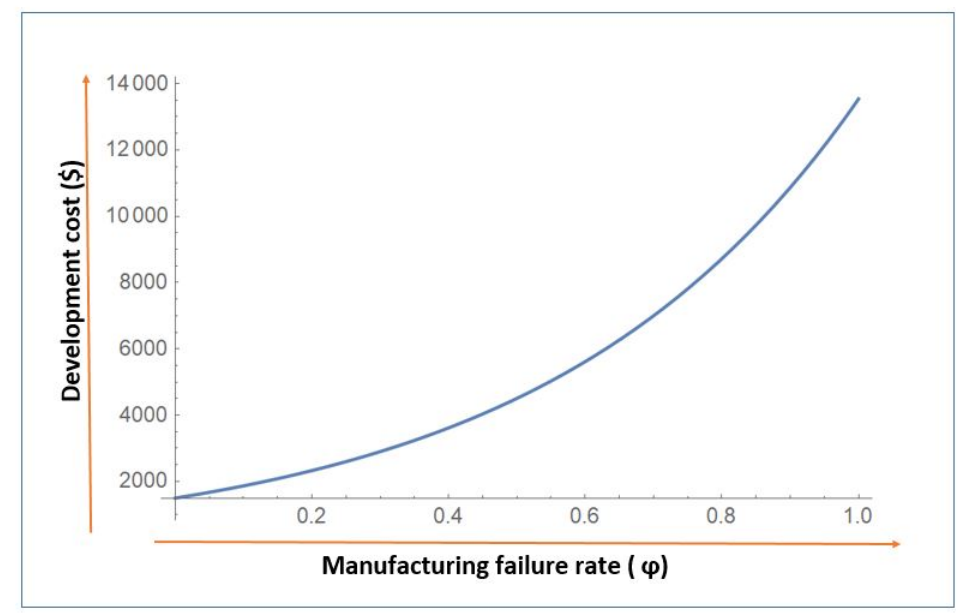

Figure 6. Change in production-technology development cost $G(p, \phi)$ with varying manufacturing reliability $(\phi)$.

\section{Inventory holding cost}

The expected inventory holding cost for Model 1 under the energy control variables is a sum of carrying cost and required energy cost for inventory, given as,

$$
\begin{aligned}
I C= & \left(C_{h}+C_{e l c} e_{h}\right) \int_{0}^{\frac{Q}{p}}\left(\int_{0}^{\frac{(p-x) t_{1}}{x}}\left(\frac{p t_{1}^{2}(p-x)}{2 x}\right) f\left(t_{2}\right) d t_{2}\right) f\left(t_{1}\right) d t_{1} \\
& \left.+\left(C_{h}+C_{e l c} e_{h}\right) \int_{0}^{\frac{Q}{p}}\left(\int_{\frac{(p-x) t_{1}}{x}}^{\infty} \frac{p t_{1}^{2}(p-x)}{2 x}\right) f\left(t_{2}\right) d t_{2}\right) f\left(t_{1}\right) d t_{1} .
\end{aligned}
$$

\section{Corrective repair cost}

On each failure, the manufacturing system is subjected to immediate corrective repair, and abort/resume (AR) inventory policy is applied. During stochastic repair time $t_{2}$, the expected energy consumption cost $E_{r}$ is given as,

$$
E_{r}\left(C_{\text {elec }}\right)=C_{\text {elc }} e_{r} t_{2}
$$

Hence, the expected repair cost is given as,

$$
R C=\left(C_{r}+C_{e l c} e_{r}\right) \int_{0}^{\frac{Q}{p}}\left(\int_{0}^{\infty} t_{2} f\left(t_{2}\right) d t_{2}\right) f\left(t_{1}\right) d t_{1}
$$


Therefore, expected total cost for Model 1 becomes,

$$
\begin{aligned}
& \operatorname{ETC}_{1}(Q, p, \phi)=S_{m}\left(1+\frac{J}{\phi}\right)+C_{\text {elc }} e_{s}+\frac{C_{\text {elc }} e_{r s}}{\phi}+A \alpha\left(\frac{p-p_{\min }}{p_{\max }-p}\right) \beta+R_{m} e^{\frac{\zeta \phi}{e}}+\int_{0}^{\frac{Q}{p}}\left(\int_{0}^{\frac{(p-x) t_{1}}{x}}\right. \\
& \left.\left(p t_{1}\left(\frac{c_{p}+C_{\text {elc }} e_{1}+\mathrm{L} \phi}{p}+C_{\text {elc }} e_{2}+(M+\mathrm{r} \phi)+p^{\gamma} \omega\right)\right) f\left(t_{2}\right) d t_{2}\right) f\left(t_{1}\right) d t_{1}+\int_{0}^{\frac{Q}{p}}\left(\int_{\frac{(p-x) t_{1}}{x}}^{\infty}\right. \\
& \left.\left(p t_{1}\left(\frac{c_{p}+C_{e l c} e_{1}+\mathrm{L} \phi}{p}+C_{e l c} e_{2}+(M+\mathrm{r} \phi)+p^{\gamma} \omega\right)\right) f\left(t_{2}\right) d t_{2}\right) f\left(t_{1}\right) d t_{1}+\left(C_{h}+C_{e l c} e_{h}\right) \int_{0}^{\frac{Q}{p}} \\
& \left(\int_{0}^{\frac{(p-x) t_{1}}{x}}\left(\frac{p t_{1}^{2}(p-x)}{2 x}\right) f\left(t_{2}\right) d t_{2}\right) f\left(t_{1}\right) d t_{1}+\left(C_{h}+C_{\text {elc }} e_{h}\right) \int_{0}^{\frac{Q}{p}}\left(\int_{\frac{(p-x) t_{1}}{x}}^{\infty}\left(\frac{p t_{1}^{2}(p-x)}{2 x}\right)\right. \\
& \left.f\left(t_{2}\right) d t_{2}\right) f\left(t_{1}\right) d t_{1}+\left(C_{r}+C_{\text {elc }} e_{r}\right) \int_{0}^{\frac{Q}{p}}\left(\int_{0}^{\infty} t_{2} f\left(t_{2}\right) d t_{2}\right) f\left(t_{1}\right) d t_{1}+C_{s} \int_{0}^{\frac{Q}{p}}\left(\int _ { \frac { ( p - x ) t _ { 1 } } { x } } ^ { \infty } \left(x t_{2}-\right.\right. \\
& \left.\left.(p-x) t_{1}\right) f\left(t_{2}\right) d t_{2}\right) f\left(t_{1}\right) d t_{1} .
\end{aligned}
$$

Similarly, the expected cycle length for Model 1 is defined as the time interval between two production runs with conditioning on the time to failure and time to repair:

$$
T_{1}(Q, p, \phi)=\int_{0}^{\frac{Q}{p}}\left(\int_{0}^{\frac{(p-x) t_{1}}{x}}\left(\frac{p t_{1}}{x}\right) f\left(t_{2}\right) d t_{2}+\int_{\frac{(p-x) t_{1}}{x}}^{\infty}\left(t_{1}+t_{2}\right) f\left(t_{2}\right) d t_{2}\right) f\left(t_{1}\right) d t_{1} .
$$

\subsection{Model 2: Random Production Capacity Model without System Failure}

When the time for stochastic failure is greater than the planned production up-time as $\left(t \geq t_{m}\right)$, then no break down is considered during production run. Hence, the expected total production cost becomes,

$$
C P_{2}(p, \phi)=\int_{\frac{Q}{p}}^{\infty}\left(Q\left(\frac{c_{p}+C_{e l c} e_{1}+\mathrm{L} \phi}{p}+C_{e l c} e_{2}+(M+\mathrm{r} \phi)+p^{\gamma} \omega\right)\right) f\left(t_{1}\right) d t_{1} .
$$

Therefore, the total costs of the system for $T C_{2}$ becomes setup cost, variable production-technology cost, variable production cost, variable energy consumption cost and variable inventory holding cost, given as,

$$
\begin{aligned}
\operatorname{ETC}_{2}(Q, p, \phi)= & S_{m}+C_{\mathrm{elc}} e_{s}+A \alpha\left(\frac{p-p_{\min }}{p_{\max }-p}\right) \beta+\left(C_{h}+C_{\text {elc }} e_{h}\right) \int_{\frac{Q}{p}}^{\infty}\left(\frac{Q^{2}(p-x)}{2 p x}\right) f\left(t_{1}\right) d t_{1} \\
& +\int_{\frac{Q}{p}}^{\infty}\left(Q\left(\frac{c_{p}+C_{\text {elc }} e_{1}+\mathrm{L} \phi}{p}+C_{\text {elc }} e_{2}+(M+\mathrm{r} \phi)+p^{\gamma} \omega\right)\right) f\left(t_{1}\right) d t_{1} .
\end{aligned}
$$

Moreover, the expected cycle length of production-inventory cycle for Model 2 is obtained as,

$$
T_{2}(Q, p, \phi)=\int_{\frac{Q}{p}}^{\infty}\left(\frac{Q}{x}\right) f\left(t_{1}\right) d t_{1} .
$$




\subsection{Integrated Stochastic Capacity-Reliability Model}

The expected total cost of integrated production-inventory model with/without stochastic failures is the sum of Models 1 and 2, which is given as,

$$
\begin{aligned}
& \operatorname{ETC}(Q, p, \phi)=S_{m}\left(1+\frac{J}{\phi}\right)+C_{\mathrm{elc}} e_{s}+\frac{C_{\mathrm{elc}} e_{\mathrm{rs}}}{\phi}+A \alpha\left(\frac{p-p_{\mathrm{min}}}{p_{\max }-p}\right) \beta+R_{m} e^{\frac{\zeta \phi}{e}}+\int_{0}^{\frac{Q}{p}}\left(\int_{0}^{\frac{(p-x) t_{1}}{x}}\right. \\
& \left.\left(p t_{1}\left(\frac{c_{p}+C_{e l c} e_{1}+\mathrm{L} \phi}{p}+C_{e l c} e_{2}+(M+\mathrm{r} \phi)+p^{\gamma} \omega\right)\right) f\left(t_{2}\right) d t_{2}\right) f\left(t_{1}\right) d t_{1}+\int_{0}^{\frac{Q}{p}}\left(\int_{\frac{(p-x) t_{1}}{x}}^{\infty}\right. \\
& \left.\left(p t_{1}\left(\frac{c_{p}+C_{e l c} e_{1}+\mathrm{L} \phi}{p}+C_{e l c} e_{2}+(M+\mathrm{r} \phi)+p^{\gamma} \omega\right)\right) f\left(t_{2}\right) d t_{2}\right) f\left(t_{1}\right) d t_{1}+\int_{\frac{Q}{p}}^{\infty}\left(Q \left(C_{e l c} e_{2}\right.\right. \\
& \left.\left.+\frac{c_{p}+C_{e l c} e_{1}+\mathrm{L} \phi}{p}+(M+\mathrm{r} \phi)+p^{\gamma} \omega\right)\right) f\left(t_{1}\right) d t_{1}+\left(C_{h}+C_{e l c} e_{h}\right) \int_{0}^{\frac{Q}{p}}\left(\int_{0}^{\frac{(p-x) t_{1}}{x}}\left(\frac{p t_{1}^{2}(p-x)}{2 x}\right)\right. \\
& \left.f\left(t_{2}\right) d t_{2}\right) f\left(t_{1}\right) d t_{1}+\left(C_{h}+C_{e l c} e_{h}\right) \int_{\frac{Q}{p}}^{\infty}\left(\frac{Q^{2}(p-x)}{2 p x}\right) f\left(t_{1}\right) d t_{1}+\left(C_{h}+C_{e l c} e_{h}\right) \int_{0}^{\frac{Q}{p}}\left(\int_{\frac{(p-x) t_{1}}{x}}^{\infty}\right. \\
& \left.\left(\frac{p t_{1}^{2}(p-x)}{2 x}\right) f\left(t_{2}\right) d t_{2}\right) f\left(t_{1}\right) d t_{1}+\left(C_{r}+C_{e l c} e_{r}\right) \int_{0}^{\frac{Q}{p}}\left(\int_{0}^{\infty} t_{2} f\left(t_{2}\right) d t_{2}\right) f\left(t_{1}\right) d t_{1}+C_{s} \int_{0}^{\frac{Q}{p}} \\
& \left(\int_{\frac{(p-x) t_{1}}{x}}^{\infty}\left(x t_{2}-(p-x) t_{1}\right) f\left(t_{2}\right) d t_{2}\right) f\left(t_{1}\right) d t_{1} .
\end{aligned}
$$

The expected cycle length from Equations (6) and (8) as a time interval, between two successive production runs is given as,

$$
\begin{aligned}
E[T](Q, p, \phi)= & \int_{0}^{\frac{Q}{p}}\left(\int_{0}^{\frac{(p-x) t_{1}}{x}}\left(\frac{p t_{1}}{x}\right) f\left(t_{2}\right) d t_{2}+\int_{\frac{(p-x) t_{1}}{x}}^{\infty}\left(t_{1}+t_{2}\right) f\left(t_{2}\right) d t_{2}\right) f\left(t_{1}\right) d t_{1} \\
& +\int_{\frac{Q}{p}}^{\infty}\left(\frac{Q}{x}\right) f\left(t_{1}\right) d t_{1} .
\end{aligned}
$$

The stochastic failure and repair rate follow continuous distribution and we have considered exponential distributions as,

$$
F\left(t_{1}\right)=1-e^{-\phi t_{1}}, \quad F\left(t_{2}\right)=1-e^{-\sigma t_{2}} .
$$

With exponential failure and repair time distributions, Equation (9) and Equation (10) becomes,

$$
\begin{aligned}
& \operatorname{ETC}(Q, p, \phi)=S_{m}\left(1+\frac{J}{\phi}\right)+\frac{C_{\text {elc }} e_{r s}}{\phi}+C_{\mathrm{elc}} e_{s}+A \alpha\left(\frac{p-p_{\min }}{p_{\max }-p}\right) \beta+R_{m} e^{\frac{\zeta \phi}{e}}+\frac{e^{-\frac{Q \phi}{p}}\left(e^{\frac{Q \phi}{p}}-1\right)}{\phi} \\
& \left(c_{p}+C_{e l c} e_{1}+C_{e l c} e_{2} p+L \phi+M p+p^{2} \omega+p r \phi\right)+\frac{\left(C_{h}+C_{e l c} e_{h}\right)(p-x) e^{-\frac{Q \phi}{p}}}{x \phi^{2}}\left(p\left(e^{\frac{Q \phi}{p}}-1\right)\right. \\
& -Q \phi)-\frac{x^{2} \phi C_{s}\left(e^{\frac{Q\left(-\frac{p \sigma}{x}+\sigma-\phi\right)}{p}}-1\right)}{\sigma(p \sigma+x(\phi-\sigma))}
\end{aligned}
$$


and

$$
\begin{aligned}
E[T](Q, p, \phi)= & \left(e ^ { - \frac { Q \phi } { p } - \frac { Q \sigma } { x } } \left(x^{2} \phi^{2} e^{\frac{Q \sigma}{p}}-\left(p \sigma^{2}(p-x)+p \sigma x \phi+x^{2} \phi^{2}\right) e^{\frac{Q \phi}{p}+\frac{Q \sigma}{x}}\right.\right. \\
& \left.\left.p \sigma+e^{\frac{Q \sigma}{x}}(p \sigma+x(\phi-\sigma))\right)\right) / \sigma x \phi(x(\sigma-\phi)-p \sigma) .
\end{aligned}
$$

Now, the expected cost per unit time is given using renewal reward theorem [52], as

$$
\operatorname{ETC}(Q, p, \phi)=t_{1} \lim _{\rightarrow} \infty \frac{E\left[\text { total cost }\left[0, t_{1}\right]\right]}{t_{1}}=\frac{E[T C](Q, p, \phi)}{E[T](Q, p, \phi)}
$$

\subsection{Solution Methodology}

In this study, production lot size $Q$, controllable production rate $p$, and manufacturing reliability $\phi$ are considered decision variables to optimize the expected total cost of system under stochastic production capacities and random energy consumption. The expected total cost of the system is a nonlinear constrained problem, whereas the goal of this paper is to optimize Equation (13) under the productivity and reliability constraints,

$$
\begin{gathered}
-Q \leq 0, \quad x<p, \quad p \leq p_{\max } \\
\phi_{\min }-\phi \leq 0, \quad \phi-\phi_{\max } \leq 0
\end{gathered}
$$

The mathematical problem is solved with Kuhn-Tucker method. Let $\lambda_{1}, \lambda_{2}, \lambda_{3}, \lambda_{4}, \lambda_{5}$ be the Lagrange multipliers corresponding to the above-mentioned constraints. Then, the Kuhn-Tucker (KT) necessary conditions for optimality are given as,

$$
\begin{gathered}
\frac{\partial E T C}{\partial Q}+\lambda_{1}=0, \frac{\partial E T C}{\partial p}-\lambda_{2}+\lambda_{3}=0, \frac{\partial E T C}{\partial \phi}-\lambda_{4}+\lambda_{5}=0 . \\
\lambda_{1} Q=0 \\
\lambda_{2}(x-p)=0, \quad \lambda_{3}\left(p_{\max }-p\right)=0 \\
\lambda_{4}\left(\phi-\phi_{\max }\right)=0, \quad \lambda_{5}\left(\phi_{\min }-\phi\right)=0 \\
\lambda_{1}, \lambda_{2}, \lambda_{3}, \lambda_{4}, \lambda_{5}, \geq 0 .
\end{gathered}
$$

To ensure the convexity of objective function, the sufficient conditions from Kuhn-Tucker must be satisfied as all principle minors should be greater than 0 . Since developed equation system ETC* for the stochastic model is a complex function with higher powers, hence it is not possible to prove its optimality through analytic validity of sufficient conditions.

\section{Numerical Experiment}

The developed model was tested with numerical analysis and sensitivity analysis of the key input parameters. The modified values of input data were obtained from $[26,28]$ and are given in Table 2. 
Table 2. General input parameter values for numerical example.

\begin{tabular}{lll}
\hline$p_{\max }=2500$ (units/unit time) & $c_{p}=1700(\$)$ & $M=10(\$ /$ per unit $)$ \\
$r=2 \$ /$ per unit & $e_{h}=8.34(\mathrm{kWh} /$ unit/unit time $)$ & $L=1500(\$)$ \\
$\gamma=1$ & $C_{\text {elc }}=0.12(\$ / \mathrm{kWh})$ & $S_{m}=1200(\$ /$ setup $)$ \\
$e_{s}=5835(\mathrm{kWh} /$ setup $)$ & $J=0.0725$ & $C_{s}=5(\$ /$ lost unit $)$ \\
$h=1.49(\$ /$ unit/unit time $)$ & $\omega=0.0015$ & $\phi_{\text {max }}=1$ \\
$\phi_{\text {min }}=0$ & $e_{r}=1700(\mathrm{kWh} /$ unit time $)$ & $\sigma=4($ repairs/unit time $)$ \\
$C_{r}=500(\$ /$ time $)$ & $\zeta=1.1$ & $x=300($ units/unit time $)$ \\
$\varrho=0.5$ & $R_{m}=1500(\$)$ & $A=200 \$$ \\
$p_{\text {min }}=300($ units/unit time $)$ & $\alpha=1.1$ & $\beta=0.01$ \\
$e_{r s}=5835(\mathrm{kWh} /$ setup $)$ & $e_{1}=8500(\mathrm{kWh} /$ unit time $)$ & $e_{2}=50(\mathrm{kWh} /$ unit $)$ \\
\hline
\end{tabular}

\subsection{Example}

The optimal results for the integrated production-maintenance policy for an unreliable manufacturing system under energy control variables is achieved as, $E T C^{*}=9253.75$ (\$/ unit time) $Q^{*}$ $=1637.4$ (units) $\quad p^{*}=1095.72$ (units/unit time), $\phi^{*}=0.24$.

The generated Hessian matrix for Equation (13) is given below. Moreover, the Hessian matrix at optimal values of decision variables is positive definite, given as,

$$
H=\left[\begin{array}{ccc}
\frac{\partial^{2} E T C}{\partial Q^{2}} & \frac{\partial^{2} E T C}{\partial Q \partial \phi} & \frac{\partial^{2} E T C}{\partial Q \partial p} \\
\frac{\partial^{2} E T C}{\partial \phi \partial Q} & \frac{\partial^{2} E T C}{\partial \phi^{2}} & \frac{\partial^{2} E T C}{\partial \phi \partial p} \\
\frac{\partial^{2} E T C}{\partial p \partial Q} & \frac{\partial^{2} E T C}{\partial p \partial \phi} & \frac{\partial^{2} E T C}{\partial p^{2}}
\end{array}\right]=\left[\begin{array}{ccc}
0.000917294 & 0.536973 & 0.000349362 \\
0.536973 & 25447.1 & -0.995246 \\
0.000349362 & -0.995246 & 0.000889964
\end{array}\right]
$$

and all eigenvalues (25447.1, $0.00124988,0.000507122$ of the matrix are positive.

The impact of required specific energy consumption for production on model parameters were tested for limits of $-70 \%$ to $+100 \%$. The graphical analysis illustrated in Figure 7 shows the impact of fixed and variable component of required specific energy for production $\left(e_{1}, e_{2}\right)$ on optimal production quantity $Q$, production rate $p$, reliability parameter $\phi$ and expected total cost of system ETC. Figure 7 shows that the expected total cost of the system is extremely sensitive to variable component of specific energy requirement.

Moreover, as the value of energy components increases, there is a constant increase in all model parameters. In the case of constant component $e_{1}$ of specific energy consumption, the unit production rate increases with an increasing value of $e_{1}$, as this part is equally distributed over the total produced units. The production lot $Q$ decreases with an increase of $e_{1}$ to reduce total cost of system. Similarly, the increases in reliability parameter suggest that, as the total cost of system increases with $e_{1}$, increased value of reliability parameter reduces the required technology development cost. On the other hand, the variable component of required specific energy $e_{2}$ shows a more sensitive relation to total cost of system and optimal production rate. Higher values of $e_{2}$ lead to a decrease in production rate to optimize the total cost of system. Similarly, the increase in $e_{2}$ leads to increase in value of reliability parameter to decrease the technology development cost for the manufacturing system. 


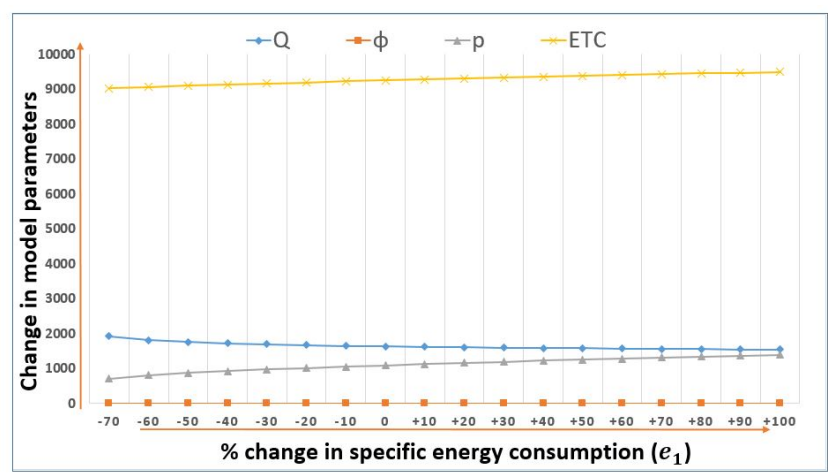

(a)

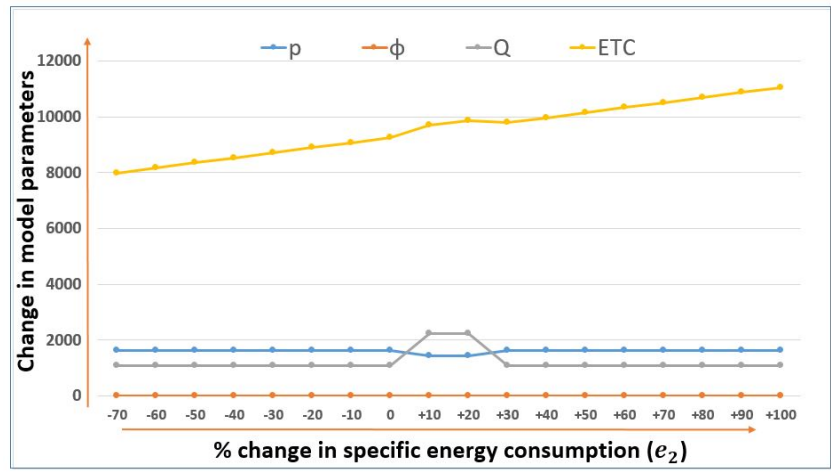

(b)

Figure 7. Change in Model parameters $(E T C, Q, p, \phi)$ of the system with respect to specific production energy parameters: (a) with varying fixed component of required energy for manufacturing $\left(e_{1}\right)$; and $(\mathbf{b})$ with varying variable component of required energy for manufacturing $\left(e_{2}\right)$.

\subsection{Sensitivity Analysis}

A sensitivity analysis was performed for all key parameters and the results are compiled in Tables 3 and 4. Sensitivity of basic model parameters related to manufacturing reliability under energy consumption is given in Table 3.

- Higher setup costs $S_{m}$ increase the total cost of manufacturing system but decrease the production rate of system. The proposed model also suggests increase in production quantity $Q$ for higher setup costs to avoid multiple setup costs. On the other hand, the restoration cost $J$ shows an increasing pattern for production quantity, production rate and expected total cost of the system. As the restoration cost depends on two parameters, setup cost and manufacturing reliability of system, the increasing value of restoration cost suggest higher production lot to avoid multiple setup requirement. In addition, it suggests higher production rates to shorten the production up-time to avoid added costs of longer production runs and possible system failure.

- For the decreasing shortage $\operatorname{cost} C_{s}$, the model shows insensitivity to production lot size. However, in the case of an increase in shortage cost in the model, we see an increase in manufacturing reliability and decrease in the production lot size.

- Inventory holding cost $h$ shows no impact on manufacturing reliability $\phi$ in this model. However, an increase in holding cost suggests an increase in production rate along with reduction of production quantity to reduce inventory accumulation. Higher inventory holding costs lead to higher system costs. The energy cost $e_{h}$ for inventory holding shows the same pattern as inventory holding cost. With decreasing energy requirements for inventory carrying, the model suggests an increase in production lot size and production rate. Manufacturing reliability is insensitive to energy requirements for inventory holding. 
- The technology development cost $R_{m}$ has direct impact on the manufacturing reliability and productivity of system. The manufacturing reliability is defined as a system-design variable and it represents the number of failures a system faces during operational hours. As the increase in technology investment $R_{m}$ shows a reduction in reliability parameter, it also reduces the production rate of system to adjust the total optimal cost of system. The production quantity increases with higher development costs, as it shows a more reliable manufacturing system.

- With the increase in corrective maintenance $\operatorname{cost} C_{r}$, the model suggests an increase in production rate to adjust the optimal total cost of the system. Higher corrective maintenance cost leads to smaller production quantities, and the expected total cost of system also increases due to higher maintenance costs. The increasing value of $\sigma$ suggest an increase in production quantity; as $\frac{1}{\sigma}$ represents the mean time to repair, as the mean time to repair decreases, the idle time for manufacturing system decreases. In addition, the model shows increase in production rate and the expected total cost of system; as the productivity of manufacturing system increases, the machine is in operational state for longer periods of time.

- As the required energy cost for system repair $e_{r}$ increases, the model shows a reduction in production quantity but increase in production rate. The reduction in production lot size explains that, as total energy required for maintenance increases, the specific energy consumption per unit for repair increases. Therefore, the model suggest an increase in production rate to optimize the production policy under energy consumption. The total expected cost also increases with an increase in required electrical energy for repair activities.

Table 4 provide a comprehensive analysis of key parameters of model under energy consumption and stochastic production capacities. From the results, the following important insights are obtained:

- Unit production cost $c_{p}$ comprises labor and specific energy consumption costs required to produce a production quantity; as the unit manufacturing cost decreases, we see an increase in production lot size of the model. In addition, with decrease in unit manufacturing cost, the expected total cost and production rate decreases. For both labor and production energy cost $E_{p}$, as the production rate decreases, the optimal reliability parameter also decreases, which is due to lower stress on the manufacturing system. Moreover, as production lot increases, reliability decreases to adjust technology development cost.

- The raw material cost $M$ and raw material yield loss cost $r$ both are highly sensitive to any increasing values of model parameters. The increase in material yield loss cost increases the production quantity and production rate simultaneously to adjust the total expected cost. In addition, it shows a reduction in the optimal reliability parameter of the model that is quite obvious; as for the manufacturing system, where raw material yield loss adds significant cost to manufacturing, higher reliability parameter is optimal for manufacturing system.

- The increase in tool/die cost $\omega$ shows a reduction in optimal production rate. As the production rate of manufacturing system increases, the added load/stress on manufacturing system increases the maintenance requirement of such machinery, and, to adjust the higher cost of production-technology development, the model suggests reduction in reliability value and optimal production rate.

- The manufacturing yield loss $L$ due to manufacturing system failures also increases the expected total cost of the system. Moreover, the increase in manufacturing yield loss cost suggests a decrease in production quantity and justifies increasing the production rate to improve the productivity of the system. The increase in yield loss value suggests reducing the manufacturing reliability parameter to minimize the negative effect of manufacturing system failures.

- As the unit cost $A$ to increase production rate by one unit decreases, the model shows an increase in production rate. With the increase in the production rate, the reliability parameter also increases. As the higher stress value increases failure frequency of manufacturing system, reliability parameter increases accordingly to adjust the technology development cost to keep 
total cost at an optimal limit. The productivity constants show quite unique trends; as the value of productivity scale parameter $\alpha$ increases, the production rate decreases continuously with an increasing trend in production quantity and expected total cost of system. However, it is insensitive towards manufacturing reliability parameter. The productivity shape parameter $\beta$ is insensitive towards expected total cost and reliability parameter of the system, however an increase in shape parameter increases the production quantity and decreases the production rate monotonically.

Table 3. Sensitivity analysis for parameters related to manufacturing reliability.

\begin{tabular}{|c|c|c|c|c|c|}
\hline Parameter & $\%$ Change & $\mathbf{Q}$ & $\phi$ & $p$ & $\%$ Change in ETC \\
\hline \multirow[t]{4}{*}{$S_{m}$} & -20 & 1611.36 & 0.24 & 1100.05 & -0.55 \\
\hline & -10 & 1615.32 & 0.24 & 1099.61 & -0.46 \\
\hline & +10 & 1654.56 & 0.24 & 1095.44 & 0.47 \\
\hline & +20 & 1673.92 & 0.24 & 1093.45 & 0.90 \\
\hline \multirow[t]{4}{*}{$J$} & -20 & 1628.46 & 0.23 & 1094.99 & -0.21 \\
\hline & -10 & 1631.75 & 0.23 & 1096.24 & -0.11 \\
\hline & +10 & 1638.27 & 0.24 & 1098.75 & 0.11 \\
\hline & +20 & 1442.67 & 0.27 & 2253.6 & 3.54 \\
\hline \multirow[t]{4}{*}{$C_{s}$} & -20 & 1635.00 & 0.23 & 1097.20 & 0.00 \\
\hline & -10 & 1635.01 & 0.23 & 1097.36 & 0.00 \\
\hline & +10 & 1435.99 & 0.27 & 2262.39 & 3.38 \\
\hline & +20 & 1436.01 & 0.27 & 2262.40 & 3.38 \\
\hline \multirow[t]{4}{*}{$h$} & -20 & 1736.89 & 0.24 & 1134.34 & -2.32 \\
\hline & -10 & 1683.17 & 0.24 & 1115.96 & -1.14 \\
\hline & +10 & 1587.60 & 0.24 & 1077.01 & 1.21 \\
\hline & +20 & 1552.56 & 0.24 & 1060.60 & 2.17 \\
\hline \multirow[t]{4}{*}{$e_{S}$} & -20 & 1635.01 & 0.23 & 1097.30 & 0.00 \\
\hline & -10 & 1635.02 & 0.23 & 1097.42 & 0.00 \\
\hline & +10 & 1435.98 & 0.27 & 2262.38 & 3.38 \\
\hline & +20 & 1435.99 & 0.27 & 2262.39 & 3.38 \\
\hline \multirow[t]{4}{*}{$e_{h}$} & -20 & 1700.41 & 0.24 & 1122.09 & -1.53 \\
\hline & -10 & 1666.54 & 0.24 & 1109.82 & -0.76 \\
\hline & +10 & 1605.64 & 0.24 & 1085.11 & 0.74 \\
\hline & +20 & 1578.21 & 0.24 & 1072.63 & 1.46 \\
\hline \multirow[t]{4}{*}{$\sigma$} & -20 & 1633.61 & 0.24 & 1095.13 & -0.01 \\
\hline & -10 & 1634.41 & 0.24 & 1096.58 & -0.01 \\
\hline & +10 & 1635.51 & 0.24 & 1098.08 & 0.00 \\
\hline & +20 & 1635.90 & 0.24 & 1099.45 & 0.00 \\
\hline \multirow[t]{4}{*}{$C_{r}$} & -20 & 1635.50 & 0.24 & 1096.00 & -0.02 \\
\hline & -10 & 1635.29 & 0.24 & 1096.66 & -0.01 \\
\hline & +10 & 1634.76 & 0.24 & 1098.33 & 0.01 \\
\hline & +20 & 1634.50 & 0.24 & 1098.33 & 0.02 \\
\hline \multirow[t]{4}{*}{$e_{r}$} & -20 & 1635.23 & 0.23 & 1096.83 & -0.01 \\
\hline & -10 & 1635.13 & 0.24 & 1097.16 & -0.00 \\
\hline & +10 & 1634.92 & 0.24 & 1097.83 & 0.00 \\
\hline & +20 & 1634.82 & 0.24 & 1098.16 & 0.01 \\
\hline \multirow[t]{4}{*}{$R_{m}$} & -20 & 1550.14 & 0.26 & 1129.66 & -1.55 \\
\hline & -10 & 1593.41 & 0.26 & 1113.23 & -0.76 \\
\hline & +10 & 1675.26 & 0.26 & 1082.32 & 0.73 \\
\hline & +20 & 1710.49 & 0.26 & 1069.04 & 1.36 \\
\hline \multirow[t]{4}{*}{$\zeta$} & -20 & 1578.13 & 0.26 & 1131.53 & -0.80 \\
\hline & -10 & 1623.86 & 0.24 & 1104.14 & -0.16 \\
\hline & +10 & 1670.69 & 0.23 & 1076.42 & 0.50 \\
\hline & +20 & 1689.53 & 0.22 & 1065.35 & 0.77 \\
\hline \multirow[t]{4}{*}{$\varrho$} & -20 & 1698.76 & 0.21 & 1059.96 & 0.89 \\
\hline & -10 & 1668.95 & 0.23 & 1077.44 & 0.48 \\
\hline & +10 & 17,278 & 0.05 & 300.06 & -7.55 \\
\hline & +20 & 22,244 & 0.05 & 300.17 & -7.76 \\
\hline
\end{tabular}


Table 4. Sensitivity analysis for parameters related to production capacity.

\begin{tabular}{|c|c|c|c|c|c|}
\hline Parameter & $\%$ Change & $\mathbf{Q}$ & $\phi$ & $p$ & $\%$ Change in ETC \\
\hline \multirow[t]{4}{*}{$c_{p}$} & -20 & 1700.58 & 0.23 & 962.96 & -1.32 \\
\hline & -25 & 1663.05 & 0.23 & 1034.12 & -0.64 \\
\hline & +10 & 1436.44 & 0.27 & 2257.64 & 3.66 \\
\hline & +20 & 1594.67 & 0.24 & 1209.48 & 1.18 \\
\hline \multirow[t]{4}{*}{$e_{1}$} & -20 & 1672.19 & 0.23 & 1018.60 & -0.62 \\
\hline & -10 & 1653.42 & 0.23 & 1058.36 & -0.31 \\
\hline & +10 & 1623.49 & 0.24 & 1131.16 & 0.30 \\
\hline & +20 & 1608.94 & 0.24 & 1166.59 & 0.58 \\
\hline \multirow[t]{4}{*}{$e_{2}$} & -20 & 1637.45 & 0.23 & 1096.31 & -3.89 \\
\hline & -10 & 1637.42 & 0.23 & 1096.02 & -1.94 \\
\hline & +10 & 1439.66 & 0.24 & 2240.77 & 4.99 \\
\hline & +20 & 1439.76 & 0.27 & 2238.81 & 6.54 \\
\hline \multirow[t]{4}{*}{$r$} & -20 & 1629.01 & 0.24 & 1105.86 & -0.39 \\
\hline & -10 & 1631.99 & 0.24 & 1101.65 & -019 \\
\hline & +10 & 1638.11 & 0.24 & 1093.39 & 0.19 \\
\hline & +20 & 1439.43 & 0.26 & 2246.64 & 3.74 \\
\hline \multirow[t]{4}{*}{$M$} & -20 & 1635.11 & 0.24 & 1098.46 & -8.03 \\
\hline & -10 & 1635.07 & 0.24 & 1097.98 & -4.02 \\
\hline & +10 & 1634.98 & 0.24 & 1097.01 & 4.02 \\
\hline & +20 & 1436.76 & 0.27 & 2249.79 & 11.36 \\
\hline \multirow[t]{4}{*}{$\omega$} & -20 & 1583.03 & 0.25 & 1248.08 & -1.41 \\
\hline & -10 & 1608.94 & 0.24 & 1166.81 & -0.68 \\
\hline & +10 & 1637.65 & 0.24 & 1091.10 & 0.07 \\
\hline & +20 & 1688.38 & 0.23 & 984.278 & 1.25 \\
\hline \multirow[t]{4}{*}{$L$} & -20 & 1640.96 & 0.24 & 1079.23 & -0.24 \\
\hline & -10 & 1638.25 & 0.24 & 1087.43 & -0.13 \\
\hline & +10 & 1631.98 & 0.23 & 1107.38 & 0.13 \\
\hline & +20 & 1629.09 & 0.23 & 1117.08 & 0.26 \\
\hline \multirow[t]{4}{*}{$A$} & -20 & 1627.73 & 0.24 & 1079.23 & -0.24 \\
\hline & -10 & 1632.59 & 0.24 & 1087.43 & -0.13 \\
\hline & +10 & 1638.06 & 0.23 & 1107.38 & 0.13 \\
\hline & +20 & 1641.09 & 0.23 & 1117.08 & 0.26 \\
\hline \multirow[t]{4}{*}{$\alpha$} & -20 & 1629.25 & 0.24 & 1098.87 & -0.12 \\
\hline & -10 & 1632.59 & 0.24 & 1098.07 & -0.05 \\
\hline & +10 & 1638.06 & 0.24 & 1096.77 & 0.06 \\
\hline & +20 & 1641.09 & 0.24 & 1096.05 & 0.13 \\
\hline \multirow[t]{4}{*}{$\beta$} & -20 & 1634.95 & 0.24 & 1097.71 & 0.00 \\
\hline & -10 & 1634.99 & 0.24 & 1097.60 & 0.00 \\
\hline & +10 & 1635.06 & 0.24 & 1097.39 & 0.00 \\
\hline & +20 & 1635.01 & 0.24 & 1097.28 & 0.00 \\
\hline
\end{tabular}

\subsubsection{Comparative Study}

This section provides a comprehensive analysis for the influence of decision variables on the expected total cost of the system. As shown in Figure 8a, as production lot size increases, the total expected cost of the system decreases to an optimal production quantity where total cost is minimum. The graph shows that ETC is not monotonically decreasing in $Q$, as there exists an optimal production lot size $Q$, after which the total expected costs starts to increase with an increase in production quantity. 


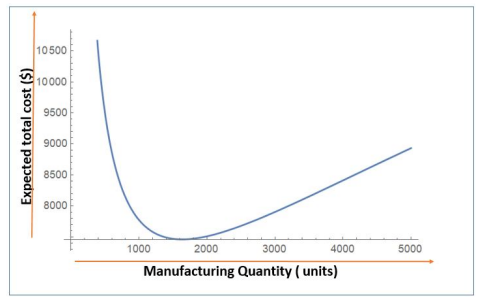

(a)

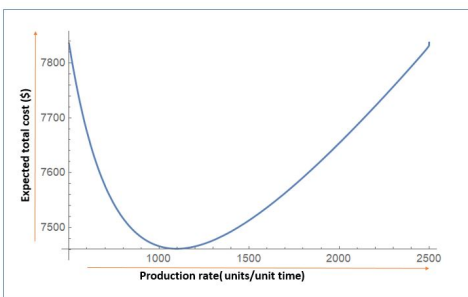

(b)

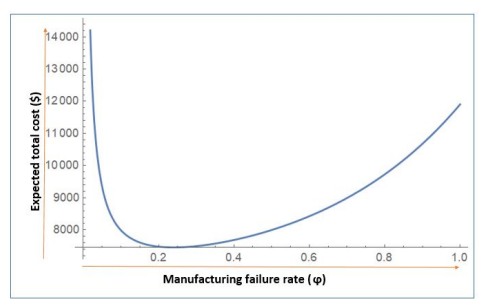

(c)

Figure 8. Change in expected total cost $\operatorname{ETC}(Q, p, \phi)$ of the system with respect to decision variables: (a) varying production quantity $(Q)$; (b) varying production rate $(p)$; and (c) varying reliability parameter $(\phi)$.

Figure $8 \mathrm{~b}$ depicts the effect of controllable production rate $p$ on the expected total cost of manufacturing system ETC. With the increase in production rate, the expected total cost decreases to a certain limit as per unit production $\operatorname{cost} C(p, \phi)$ is a function of production rate, after which it starts to increase again. The higher production rate also results in lower specific energy consumption per unit of production as more items are produced in less production up-time. However, increase in production rate increases other cost components of per unit production cost, i.e., tool/die cost, thus we see an increase in total cost after the optimal limit for model, which is 1095.72 (units/unit time). The expected total cost ETC monotonically increases with manufacturing reliability parameter $\phi$, as shown in Figure 8c. As the failure rate of manufacturing system increases, the total cost increases due to productivity loss, and extra costs of repair, energy consumption, and resulted idle time in manufacturing process.

As shown in Figure 9, the expected unit production $\operatorname{cost} C(p, \phi)$ monotonically increases with manufacturing unreliability. As the failure rate of manufacturing system increases, the expected unit production cost increases due to productivity loss, extra costs of repair and idle time. The production rate shows a rather different relation with expected unit production cost. As the production rate increases, the expected unit production cost decreases to an optimal point, after which it starts to increase.

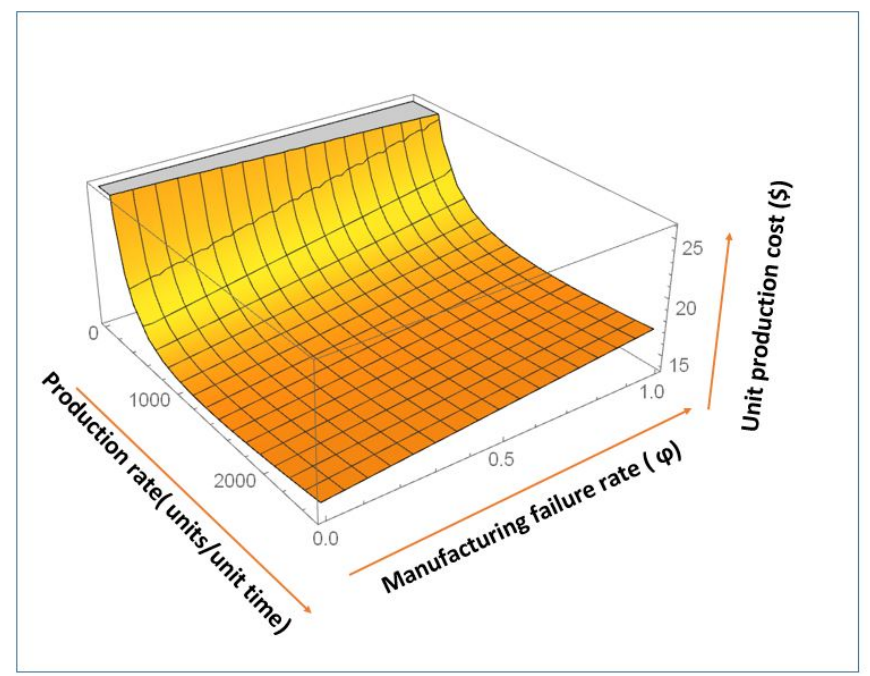

Figure 9. Change in expected unit manufacturing $\operatorname{cost} c(p, \phi)$ with varying manufacturing reliability $(\phi)$ and production rate $(p)$.

As the repair rate increases, time for each repair $t_{2}$ decreases and eventually energy consumption per repair decreases, which leads to a decrease in repair cost for manufacturing system, as shown in Figure 10. 


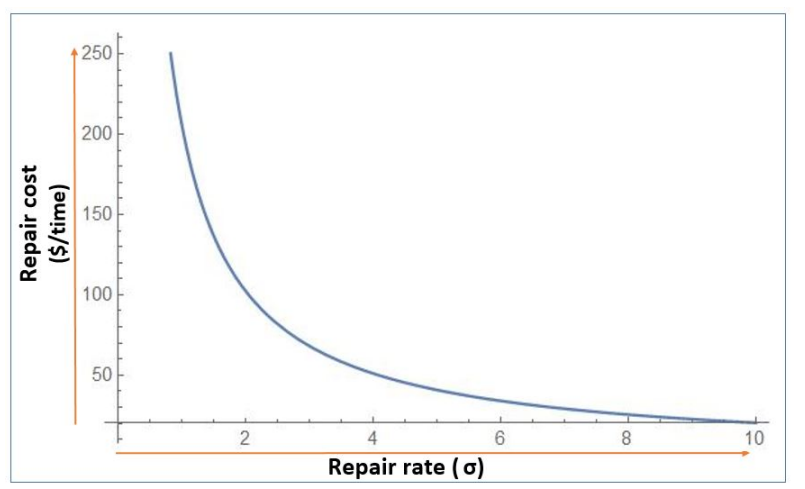

Figure 10. Change in energy consumption per machine repair $\operatorname{SEC}(\sigma)$ with varying repair rate $(\sigma)$.

Figure 11a shows the relationship of the expected total cost ETC with manufacturing unreliability. As the failure rate of manufacturing system increases, the expected unit production cost also increases. With an increase in unit production rate, the expected total cost of system decreases because the unit production cost is the sum of manufacturing cost and energy consumption for production and, with an increase in production rate, the energy cost decreases [44]. Figure 11b shows the relationship of the expected total cost ETC with manufacturing quantity and production rate. The manufacturing quantity shows a convex relationship with expected total cost of system. Figure 11c shows the relationship of the expected total cost ETC with manufacturing quantity and manufacturing reliability parameter. The manufacturing quantity shows a convex relationship with expected total cost of system. ETC increases monotonically with increase in failure rate of manufacturing system.

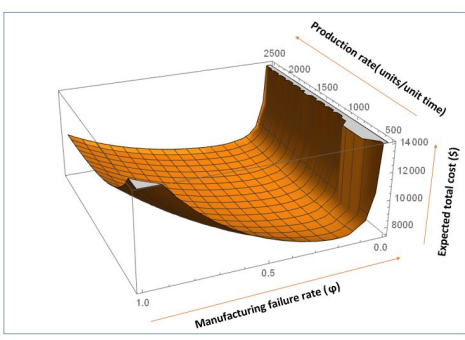

(a)

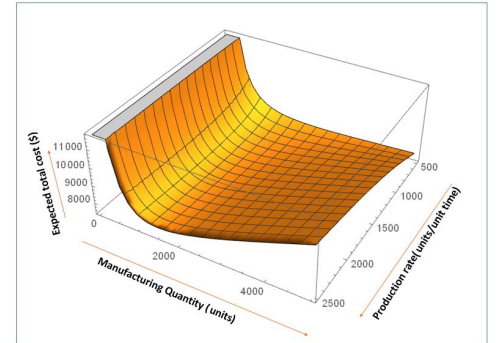

(b)

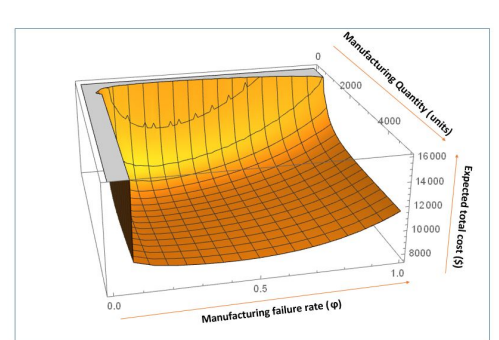

(c)

Figure 11. Change in expected total $\operatorname{cost} \operatorname{ETC}(Q, p, \phi)$ of the system with respect to decision parameters: (a) varying manufacturing reliability parameter and production rate $(\phi, p)$; (b) varying manufacturing quantity and production rate $(Q, p)$; and (c) varying manufacturing quantity and manufacturing reliability parameter $(Q, \phi)$.

\subsubsection{Managerial Insights}

- The study provides a better understanding of production-maintenance policy for stochastic production capacities under random failure rates, random repair rates and energy consumption requirements.

- By employing precise cost data of related cost factors associated with unreliable manufacturing systems, production and maintenance managers can set an optimum level of manufacturing reliability that minimizes the overall maintenance and energy consumption costs.

- Random breakdowns of manufacturing system represent an inevitable phenomenon, which is considered in many maintenance planning models for energy consumption, but the effect of random repair rate is usually ignored. This study also gives insights into the simultaneous improvement of reliability and manufacturing productivity when managers faces the challenge of uncertain production capacities due to longer repair times. 
- The increase in tool/die cost shows a reduction in optimal production rate. As the production rate of manufacturing system increases, the added load and stress increases the maintenance requirement of such machinery, and to adjust the higher cost of production-technology development, the model suggests reductions in reliability value and processing speeds.

- For controllable production rates, the added expenditure of maintenance and technology development investment are also considered; therefore, managers can also look into possible technology development needed to improve productivity of manufacturing systems.

- This paper presents the relevant relationships between variable energy consumption rates and constituents related to stochastic production capacities and maintenance management plans. Improved production and maintenance planning will allow managers to increase production rates and reduce energy consumption per unit of production quantity. Furthermore, through additional production and technology development policies, machine breakdowns can be reduced.

\section{Conclusions}

This study investigated an integrated production-maintenance-inventory system with some realistic assumptions. For an unreliable manufacturing system, the manufacturing capacity is considered stochastic as it depends on the random failure rate, repair rate and production rate of manufacturing system, which follow exponential distributions. Hence, the energy consumption for each production cycle is also considered random for unreliable manufacturing systems. The developed stochastic model is optimized for production lot size, production rate and reliability parameter. The practical implications of model are shown through sensitivity analysis and comparative study of model parameters.

- The study suggested that it is not practical to consider constant production rates in an unreliable manufacturing system; as the system faces random failure rate and random repair rate, the productivity of system is highly affected due to manufacturing unreliability. In such a scenario, controllable production rates help in increasing the production capacity of a manufacturing system.

- As the productivity of a manufacturing system depends on its reliability and operational condition, the unit production cost of a manufacturing system is considered as a function of controllable production rate, which varies within design limits, manufacturing reliability, labor costs and variable energy costs.

- The manufacturing system productivity and reliability can be further enhanced through investment in advance technology, better and improved resources and skilled labor. Therefore, a production-technology development cost is introduced as a function of manufacturing reliability. For improved efficiency of manufacturing process, a productivity investment is also introduced in manufacturing costs to get optimal level of variable processing speeds for an unreliable manufacturing system.

- The cost of electrical energy consumption for simultaneous production, inventory and maintenance planning is not considered in the existing literature, therefore this study introduces the energy cost components for operational and idle states of production setups, restoration, production, inventory holding and repair cost.

- A limitation of the study is considering deterministic demand, where random demand of products is a more realistic phenomena. In addition, only electrical energy consumption is considered in this study, whereas production firms usually use more than one type of energy sources in production. The model can be further extended with the case of imperfect production process, inspection policies and economic factors such as inflation and time value of money. Moreover, integrated production-maintenance policies under uncertain production environments are worthy of investigation, as discussed in [53]. The study can be further extended to the concept [54] of 
imperfect production process for an unreliable manufacturing system, as production of defectives is inevitable.

Author Contributions: Conceptualization, I.A. and S.K.; Methodology, I.A.; Software, I.A.; Validation, B.S.; Formal analysis, I.A; Investigation, B.S. and I.A; Resources, B.S., I.A., and S.K.; Data curation, B.S., I.A and S.K.; Writing - original draft preparation, I.A; Writing—review and editing, I.A; Visualization, I.A. and S.K.; Supervision, B.S.

Funding: This work was supported by reserach fund of Hanyang University (HY-2018-F), under (Project Number: 201800000001370).

Conflicts of Interest: The authors declare no conflicts of interest.

\section{Abbreviations}

The following abbreviations are used in this paper.

EMQ Economic manufacturing quantity

$\mathrm{O} 2 \mathrm{O}$ Online to Offline

AR Abort/Resume

KT Kuhn-Tucker method

SEC Specific energy consumption

EEPP Energy efficient production planning

\section{References}

1. Sarkar, B.; Guchhait, R.; Sarkar, M.; Pareek, S.; Kim, N. Impact of safety factors and setup time reduction in a two-echelon supply chain management. Robot. Comput.-Integr. Manuf. 2019, 55, 250-258. [CrossRef]

2. Ciavotta, M.; Meloni, C.; Pranzo, M. Minimising general setup costs in a two-stage production system. Int. J. Prod. Res. 2013, 51, 2268-2280. [CrossRef]

3. Kumar, V.; Sarkar, B.; Sharma, A.N.; Mittal, M. New product launching with pricing, free replacement, rework, and warranty policies via genetic algorithmic approach. Int. J. Comput. Int. Syst. 2019, 12, 519-529. [CrossRef]

4. Sarkar, B.; Guchhait, R.; Sarkar, M.; Cárdenas-Barrón, L.E. How does an industry manage the optimum cash flow within a smart production system with the carbon footprint and carbon emission under logistics framework? Int. J. Prod. Econ. 2019, 213, 243-257. [CrossRef]

5. Shibin, K.; Gunasekaran, A.; Papadopoulos, T.; Childe, S.J.; Dubey, R.; Singh, T. Energy sustainability in operations: An optimization study. Int. J. Adv. Manuf. Technol. 2016, 86, 2873-2884. [CrossRef]

6. Bazan, E.; Jaber, M.Y.; Zanoni, S. Supply chain models with greenhouse gases emissions, energy usage and different coordination decisions. Appl. Math. Model. 2015, 39, 5131-5151. [CrossRef]

7. Giret, A.; Trentesaux, D.; Prabhu, V. Sustainability in manufacturing operations scheduling: A state of the art review. J. Manuf. Syst. 2015, 37, 126-140. [CrossRef]

8. Liu, Y.; Dong, H.; Lohse, N.; Petrovic, S.; Gindy, N. An investigation into minimising total energy consumption and total weighted tardiness in job shops. J. Clean. Prod. 2014, 65, 87-96. [CrossRef]

9. Biel, K.; Glock, C.H. Systematic literature review of decision support models for energy-efficient production planning. Comput. Ind. Eng. 2016, 101, 243-259. [CrossRef]

10. Liu, Y.; Dong, H.; Lohse, N.; Petrovic, S. A multi-objective genetic algorithm for optimisation of energy consumption and shop floor production performance. Int. J. Prod. Econ. 2016, 179, 259-272. [CrossRef]

11. Rapine, C.; Penz, B.; Gicquel, C.; Akbalik, A. Capacity acquisition for the single-item lot sizing problem under energy constraints. Omega 2018, 81, 112-122. [CrossRef]

12. Mousavi, S.; Thiede, S.; Li, W.; Kara, S.; Herrmann, C. An integrated approach for improving energy efficiency of manufacturing process chains. Int. J. Sustain. Eng. 2016, 9, 11-24. [CrossRef]

13. González-Romera, E.; Ruiz-Cortés, M.; Milanés-Montero, M.I.; Barrero-González, F.; Romero-Cadaval, E.; Lopes, R.A.; Martins, J. Advantages of minimizing energy exchange instead of energy cost in prosumer microgrids. Energies 2019, 12, 719. [CrossRef]

14. Mori, M.; Fujishima, M.; Inamasu, Y.; Oda, Y. A study on energy efficiency improvement for machine tools. CIRP Ann. 2011, 60, 145-148. [CrossRef] 
15. Shrouf, F.; Ordieres-Meré, J.; García-Sánchez, A.; Ortega-Mier, M. Optimizing the production scheduling of a single machine to minimize total energy consumption costs. J. Clean. Prod. 2014, 67, 197-207. [CrossRef]

16. Tang, D.; Dai, M.; Salido, M.A.; Giret, A. Energy-efficient dynamic scheduling for a flexible flow shop using an improved particle swarm optimization. Comput. Ind. 2016, 81, 82-95. [CrossRef]

17. Dai, M.; Tang, D.; Giret, A.; Salido, M.A.; Li, W.D. Energy-efficient scheduling for a flexible flow shop using an improved genetic-simulated annealing algorithm. Robot. Comput.-Integr. Manuf. 2013, 29, 418-429. [CrossRef]

18. Li, X.; Xing, K.; Wu, Y.; Wang, X.; Luo, J. Total energy consumption optimization via genetic algorithm in flexible manufacturing systems. Comput. Ind. Eng. 2017, 104, 188-200. [CrossRef]

19. Calicioglu, O.; Flammini, A.; Bracco, S.; Bellù, L.; Sims, R. The Future Challenges of Food and Agriculture: An integrated analysis of trends and solutions. Sustainability 2019, 11, 222. [CrossRef]

20. Pramangioulis, D.; Atsonios, K.; Nikolopoulos, N.; Rakopoulos, D.; Grammelis, P.; Kakaras, E. A Methodology for Determination and Definition of Key Performance Indicators for Smart Grids Development in Island Energy Systems. Energies 2019, 12, 242. [CrossRef]

21. Brahman, F.; Honarmand, M.; Jadid, S. Optimal electrical and thermal energy management of a residential energy hub, integrating demand response and energy storage system. Energy Build. 2015, 90, 65-75. [CrossRef]

22. Shojafar, M.; Cordeschi, N.; Baccarelli, E. Energy-efficient adaptive resource management for real-time vehicular cloud services. IEEE Tran. Cloud Comput. 2016, 7, 196-209. [CrossRef]

23. Sarkar, B.; Tayyab, M.; Choi, S.B. Product Channeling in an O2O supply chain management as power transmission in electric power distribution systems. Mathematics 2019, 7, 4. [CrossRef]

24. Bazan, E.; Jaber, M.Y.; Zanoni, S. Carbon emissions and energy effects on a two-level manufacturer-retailer closed-loop supply chain model with remanufacturing subject to different coordination mechanisms. Int. J. Prod. Econ. 2017, 183, 394-408. [CrossRef]

25. Bazan, E.; Jaber, M.Y.; El Saadany, A.M. Carbon emissions and energy effects on manufacturingremanufacturing inventory models. Comput. Ind. Eng. 2015, 88, 307-316. [CrossRef]

26. Sarkar, M.; Sarkar, B.; Iqbal, M. Effect of energy and failure rate in a multi-item smart production system. Energies 2018, 11, 2958. [CrossRef]

27. Devoldere, T.; Dewulf, W.; Deprez, W.; Willems, B.; Duflou, J.R. Improvement potential for energy consumption in discrete part production machines. In Advances in Life Cycle Engineering for Sustainable Manufacturing Businesses; Springer: London, UK, 2007; pp. 311-316.

28. Sarkar, B.; Sana, S.S.; Chaudhuri, K. Optimal reliability, production lotsize and safety stock: An economic manufacturing quantity model. Int. J. Manag. Sci. Eng. Manag. 2010, 5, 192-202. [CrossRef]

29. Sarkar, B.; Sana, S.S.; Chaudhuri, K. Optimal reliability, production lot size and safety stock in an imperfect production system. Int. J. Math. Oper. Res. 2010, 2, 467-490. [CrossRef]

30. Sarkar, B. An inventory model with reliability in an imperfect production process. App. Math. Comput. 2012, 218, 4881-4891. [CrossRef]

31. Bhuniya, S.; Sarkar, B.; Pareek, S. Multi-product production system with the reduced failure rate and the optimum energy consumption under variable demand. Mathematics 2019, 7, 465. [CrossRef]

32. Yao, X.; Zhou, J.; Zhang, J.; Boër, C.R. From intelligent manufacturing to smart manufacturing for Industry 4.0 driven by next generation artificial intelligence and further On. In Proceedings of the 2017 5th International Conference on Enterprise Systems (ES), Beijing, China, 22-24 September 2017; IEEE: Piscataway, NJ, USA, 2017; pp. 311-318.

33. Sarkar, B.; Mandal, P.; Sarkar, S. An EMQ model with price and time dependent demand under the effect of reliability and inflation. App. Math. Comput. 2014, 231, 414-421. [CrossRef]

34. Glock, C.H. Batch sizing with controllable production rates. Int. J. Prod. Res. 2010, 48, 5925-5942. [CrossRef]

35. Shepherd, R.W. Theory of Cost and Production Functions; Princeton University Press: Princeton, NJ, USA, 2015.

36. Rishel, R. Control of systems with jump Markov disturbances. IEEE Trans. Autom. Control 1975, 20, $241-244$. [CrossRef]

37. Olsder, G.; Suri, R. Time-optimal control of parts-routing in a manufacturing system with failure-prone machines. In Proceedings of the 1980 19th IEEE Conference on Decision and Control including the Symposium on Adaptive Processes, Albuquerque, NM, USA, 10-12 December 1980; IEEE: Piscataway, NJ, USA, 1980; pp. 722-727. 
38. Glock, C.H. Batch sizing with controllable production rates in a multi-stage production system. Int. J. Prod. Res. 2011, 49, 6017-6039. [CrossRef]

39. Khouja, M.; Mehrez, A. Economic production lot size model with variable production rate and imperfect quality. J. Oper. Res. Soc. 1994, 45, 1405-1417. [CrossRef]

40. Sarkar, M.; Hur, S.; Sarkar, B. Effects of variable production rate and time-dependent holding cost for complementary products in supply chain model. Math. Probl. Eng. 2017, 2017, 2825103. [CrossRef]

41. Alfares, H.K.; Ghaithan, A.M. EOQ and EPQ Production-Inventory Models with Variable Holding Cost: State-of-the-Art Review. Arab. J. Sci. Eng. 2019, 44, 1737-1755. [CrossRef]

42. Dey, B.K.; Sarkar, B.; Pareek, S. A two-echelon supply chain management with setup time and cost reduction, quality improvement and variable production rate. Mathematics 2019, 7, 328. [CrossRef]

43. Khalifehzadeh, S.; Fakhrzad, M. A Modified Firefly Algorithm for optimizing a multi stage supply chain network with stochastic demand and fuzzy production capacity. Comput. Ind. Eng. 2019, 133, 42-56. [CrossRef]

44. Marchi, B.; Zanoni, S.; Jaber, M.Y. Economic production quantity model with learning in production, quality, reliability and energy efficiency. Comput. Ind. Eng. 2019, 129, 502-511. [CrossRef]

45. Marchi, B.; Zanoni, S.; Zavanella, L.; Jaber, M. Supply chain models with greenhouse gases emissions, energy usage, imperfect process under different coordination decisions. Int. J. Prod. Econ. 2019, 211, 145-153. [CrossRef]

46. Adane, T.; Nicolescu, M. Towards a Generic Framework for the Performance Evaluation of Manufacturing Strategy: An Innovative Approach. J. Manuf. Mater. Process. 2018, 2, 23. [CrossRef]

47. Demichela, M.; Baldissone, G.; Darabnia, B. Using field data for energy efficiency based on maintenance and operational optimisation. A step towards PHM in process plants. Processes 2018, 6, 25. [CrossRef]

48. Rackow, T.; Kohl, J.; Canzaniello, A.; Schuderer, P.; Franke, J. Energy Flexible Production: Saving Electricity Expenditures by Adjusting the Production Plan. Procedia CIRP 2015, 26, 235-240. [CrossRef]

49. Lee, S.; Prabhu, V.V. Energy-aware feedback control for production scheduling and capacity control. Int. J. Prod. Res. 2015, 53, 7158-7170. [CrossRef]

50. Gutowski, T.; Dahmus, J.; Thiriez, A. Electrical energy requirements for manufacturing processes. In Proceedings of the 13th CIRP International Conference on Life Cycle Engineering, Leuven, Belgium, 31 May-2 June 2006; Volume 31, pp. 623-638.

51. Prevention, I.P. Control Reference Document on Best Available Techniques for Large Combustion Plants; European Commission: Brussels, Belgium, 2006.

52. Ross, S.M. Introduction to Probability Models; Academic Press: Cambridge, MA, USA, 2014.

53. Dellino, G.; Kleijnen, J.P.; Meloni, C. Robust optimization in simulation: Taguchi and response surface methodology. Int. J. Prod. Econ. 2010, 125, 52-59. [CrossRef]

54. Sarkar, B.; Majumder, A.; Sarkar, M.; Kim, N.; Ullah, M. Effects of variable production rate on quality of products in a single-vendor multi-buyer supply chain management. Int. J. Adv. Manuf. Technol. 2018, 99, 567-581. [CrossRef]

(C) 2019 by the authors. Licensee MDPI, Basel, Switzerland. This article is an open access article distributed under the terms and conditions of the Creative Commons Attribution (CC BY) license (http://creativecommons.org/licenses/by/4.0/). 